\title{
Vino, turismo e innovación: las Rutas del Vino de España, una estrategia integrada de desarrollo rural
}

\author{
BELÉN MIRANDA ESCOLAR \\ Departamento de Economía Aplicada, UNIVERSIDAD DE VALLADOLID, \\ ESPAÑA. E-mail: belen@eco.uva.es
}

RICARDO FERNÁNDEZ MORUECO

Servicio Territorial de Agricultura y Ganadería de Zamora, JUNTA DE CASTILLA Y LEÓN, ESPAÑA. E-mail: fermorri@jcyl.es

\begin{abstract}
RESUMEN
La importancia del viñedo en la economía agraria a lo largo de la historia es incuestionable. La búsqueda de la calidad de los vinos en un mercado cada vez más competitivo y globalizado es un objetivo de todas las comarcas vitícolas del mundo. En este contexto, el afán por innovar y ofrecer al consumidor productos más diversificados y complementarios al propio vino ha llevado a la creación de una amplia oferta enoturística, articulada en muchas ocasiones en torno a las denominadas rutas del vino. Con el ánimo de garantizar al turista un producto turístico de alta calidad, se ha creado el producto Rutas del Vino de España, basado en la idea de que el vino puede ser considerado un "producto intensivo en territorio" (PIT) al contener un elevado componente territorial referido al lugar en el que se produce.
\end{abstract}

Palabras clave: Desarrollo rural, distrito industrial, enoturismo, viñedo, vino.

\section{Wine, Tourism and Innovation: the Wine Routes of Spain, an Integrated Strategy of Rural Development}

\begin{abstract}
The importance of the vineyard in the agricultural economy throughout history is unquestionable. The quest for quality wines in a market increasingly competitive and globalized world is a goal of all wine regions in the world. In this context, the effort to innovate and to provide consumers more diversified and complementary products to the wine itself has led to the creation of a wide range of wine tourism, articulated on many occasions about the so-called wine routes. With the aim to guarantee the visitor a high quality tourism product, it has created the product Wine Routes of Spain, based on the idea that wine can be defined as a "territorial intensive product" (TIP) since it contains a strong reference in the territory in which it is produced.
\end{abstract}

Keywords: Rural development, industrial district, wine tourism, vineyard, wine.

Clasificación JEL: L66, L83, N54, Q26

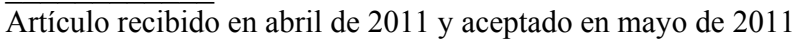

Artículo disponible en versión electrónica en la página www.revista-eea.net, ref. ə-29117 


\section{INTRODUCCIÓN}

El vino es el alimento natural obtenido exclusivamente por fermentación alcohólica, total o parcial, de uva fresca, estrujada o no, o de mosto de uva ${ }^{1}$. Pero el vino no es sólo un alimento; es un símbolo de la cultura occidental, un testigo de la evolución de los pueblos, una forma de socialización, un ejemplo de innovación tecnológica y hasta una muestra de refinamiento. Es, además, el único alimento que tiene una ley específica aprobada por las Cortes Generales, debido a sus peculiaridades, a sus características organolépticas y a sus implicaciones económicas, sociales, agronómicas y ambientales.

Son numerosas las muestras que se pueden encontrar a lo largo de la historia y de la literatura para dar testimonio de lo que es y supone el vino en nuestra cultura. Plinio el Viejo escribía que "gracias al vino, el hombre es el único animal que bebe sin tener sed"; en El Lazarillo de Tormes (anónimo), obra maestra de la picaresca española publicada en 1554, se decía: "Yo, como estaba hecho al vino, moría por él...”; Francisco de Quevedo, en su poesía Dijo la rana al mosquito, escribió: "Dijo la rana al mosquito desde una tinaja: más quiero morir en el vino que vivir en el agua"; y, José Ortega y Gasset explicaba que "el vino da brillantez a las campiñas, exalta los corazones, enciende las pupilas y enseña a los pies la danza”.

Pero no son menos las referencias que encontramos en la historia del pensamiento económico y que utilizan el vino como ejemplo para desarrollar y explicar numerosos conceptos Aunque somos conscientes de que un análisis exhaustivo de estas aportaciones nos habría retrotraído mucho más en el tiempo, no es éste el objeto del presente trabajo. Comenzando por Adam Smith y su obra maestra Investigación acerca de la Naturaleza y Causas de la Riqueza de las Naciones, pueden encontrarse numerosas citas que relacionan teoría económica y vino ${ }^{2}$, como, por ejemplo, cuando explica que los precios más altos del vino, especialmente del vino de calidad, pueden ser el resultado de factores: de la oferta, "no hay fruto en que más influya la variedad de terrenos que el vino"; de la demanda, "la cantidad que de ellos (vinos) puede ponerse en estado de venta nunca llega a satisfacer la efectiva demanda"; o de ambas (Smith, 1776; 1794, pp.267-271). O cuando habla de "las rentas de aquellas tierras que producen unos frutos singularmente estimados, como de algunos viñedos de España y Francia” (Smith, 1776; 1794, p.102).

David Ricardo utiliza el vino para ilustrar su teoría del valor cuando señala que "existen algunas cosas cuyo valor es determinado solamente por su escasez

1 Definición que proporciona el artículo 2 de la Ley 24/2003, de 10 de julio, de la Viña y del Vino.

2 Este hecho ha llevado a algunos autores (Veseth, 2008) a calificar a Adam Smith como el "padre de la economía [del vino]". 
(...) Entre éstas figuran los vinos de calidad especial que sólo pueden elaborarse a partir de uvas cosechadas en una región determinada y de las que sólo existe una cantidad muy limitada" (Ricardo, 1817; 1985, p.28). También recurre al vino para demostrar las ganancias que pueden obtenerse a través del comercio y que sintetizó en su conocida teoría de la ventaja comparativa ${ }^{3}$. Explicó su teoría utilizando como ejemplo el intercambio de tejidos u otras mercancías procedentes de Inglaterra por vino portugués. Inglaterra tenía una ventaja comparativa en tejidos y Portugal en vino y ambos ganaban con el comercio (Ricardo, 1817; 1985, p.124-12). Por qué Ricardo elige el vino, y por qué vino portugués y no francés, puede ayudarnos a comprender la relación que existe entre ciertos acontecimientos y el vino en el desarrollo del pensamiento económico. Como es sabido, Ricardo fue un acérrimo defensor del libre comercio, al igual que Adam Smith, y en reiteradas ocasiones se manifestó a favor de que se abolieran las Leyes Inglesas sobre los Cereales, por las que se establecían fuertes aranceles sobre las importaciones. En aquella época los aranceles sobre el vino francés fueron tan altos que se convirtió en un producto prohibitivo y, en consecuencia, prácticamente no entraba nada de vino francés en Inglaterra (Chaikind, 2010).

También Karl Marx menciona el vino en diferentes textos, y en una interesante nota lo utiliza como un ejemplo de explotación, al igual que John Stuart Mill, cuando se refiere al vino para explicar las limitaciones que existen a corto plazo para obtener una determinada cantidad de producto (por las peculiares condiciones de suelo, clima y maduración que requiere), o Alfred Marshall, que nos remite al vino de calidad como ejemplo de bien con una alta elasticidad precio de la demanda.

Éstos son tan sólo unos cuantos ejemplos que demuestran que el viñedo, la viticultura y el vino estuvieron presentes en los inicios del desarrollo del pensamiento económico. Sin embargo, resulta interesante comprobar que cuando el corpus de la teoría económica creció y las economías modernas se hicieron más complejas, el vino aparecía citado con menor frecuencia. Por ejemplo, resulta extraño que no exista ninguna referencia al vino en la obra maestra de Thorstein Veblen ${ }^{4}$, Teoría de las clase ociosa $(1899 ; 1971)$, en la que estudia los dos motivos por los que los individuos consumen bienes: i) satisfacer las necesidades físicas; y, ii) emular el comportamiento de otros, lo que él denomina consumo ostentoso y derrochador, que generalmente se realiza para demostrar el status social.

\footnotetext{
${ }^{3}$ Explicada en su obra Principios de Economía Política y Tributación publicada en 1817.

${ }^{4}$ Esta ausencia podría explicarse quizá porque la obra fue escrita durante el período en el que se produjo una gran plaga de la filoxera.
} 
Son muchas las pasiones que levanta el vino pero también son abundantes las polémicas desatadas en torno a él: un sector, considerado por muchos, excesivamente regulado que limita la "libertad de hacer", intervención o liberalización; a esta última opción habrá que apuntarse a partir de 2015 si la norma reguladora no cambia; un aprovechamiento indebido de la imagen de marca que han adquirido determinadas denominaciones de calidad y los territorios en los que éstas se ubican, dando lugar a situaciones de competencia desleal en las que han tenido que mediar los Tribunales de Justicia; pero también un sector con importantes efectos de arrastre sobre otras actividades económicas que utilizan el vino como input o como output; un sector en el que la innovación de todo tipo está presente, sobre todo en los últimos años, para hacer frente a la dura competencia a la que le somete las exigencias de un mercado cada vez más complejo. Es en este contexto en el que se inserta el enoturismo y el producto Rutas del Vino de España, como una vía para diversificar aún más la oferta que puede generarse a partir de este "néctar de los dioses" que puede ser considerado un "producto intensivo en territorio" (PIT), por el fuerte vínculo que tiene con el lugar en el que se produce. En definitiva, en este trabajo deseamos poner de manifiesto que nos encontramos ante un sector estratégico para el desarrollo de muchas áreas rurales de España, en el que la innovación adquiere un lugar preponderante.

\section{VINO Y REGULACIÓN: “NI CONTIGO NI SIN TI, TIENEN MIS MALES REMEDIO”}

Conocer con exactitud cuándo y dónde se elaboró el primer vino es una tarea imposible, aunque sí se puede realizar una aproximación a través de distintos descubrimientos e investigaciones que ofrecen indicios de los orígenes de lo que hoy se conoce como vino. Junto al río Jordán se han encontrado, en diferentes tumbas, cartuchos de plata con restos de vides que muestran ciertos rasgos que diferencian las vides silvestres de las cultivadas. Del mismo modo, algunas pinturas egipcias de hace casi 5.000 años reflejan el cultivo de la vid, la producción de vino, su almacenamiento y el placer que proporciona su consumo.

En España, hace más de 3.000 años, los fenicios ya cultivaban la vid y el tiempo transcurrido hasta la actualidad ha sido un devenir de acontecimientos. A finales del siglo XIX y principios del XX la filoxera arrasó el cultivo en España lo que obligó a realizar la primera gran reconversión. Las contiendas bélicas que se desencadenaron en Europa y España a lo largo del siglo XX, y la consiguiente necesidad de obtener alimentos de primera necesidad, relegó el cultivo del viñedo en muchas regiones a zonas marginales. El Estatuto de la 
Viña, del Vino y de los Alcoholes de $1970^{5}$ permitió dar un paso hacia delante en la regulación, promoción y protección de los vinos de calidad, y la incorporación de España a la Comunidad Económica Europea en 1986 supuso, entre otros muchos cambios, la incorporación del acervo comunitario, la llegada de cuantiosas sumas de dinero para la reconversión y reestructuración de un viñedo productor de vino excedentario y de poca calidad en algunas regiones, $\mathrm{y}$ el fomento definitivo de las comarcas productoras de vinos de calidad a través de figuras como los Vinos de Calidad Producidos en Regiones Determinadas (vcprd) y, principalmente, las Denominaciones de Origen $(D O)^{6}$.

De esta manera, España logró entrar en un mercado, el de la Unión Europea, que en la campaña 2007/08 produjo 165,5 millones de hectolitros a partir de una superficie de viñedo de 3,5 millones de hectáreas y que representa el $65 \%$ del comercio mundial. En este nuevo contexto, la regulación era un hecho y, en ocasiones, hasta una necesidad.

Como es sabido, la regulación del sector se realiza a través de la Organización Común de Mercados Agrícolas $(\mathrm{OCM})^{7}$. En los primeros Reglamentos, el sector vitivinícola no limitaba la plantación y disponía de muy pocos instrumentos de regulación del mercado que permitieran hacer frente a las fuertes oscilaciones anuales de la producción y de los precios. Posteriormente, se estableció una cuasi-garantía de venta, lo que generó excedentes estructurales importantes. A finales de la década de los setenta, se estableció la prohibición de plantar y la obligación de destilar los excedentes y, a finales de los ochenta, se incentivó de forma importante el arranque de viñedos ${ }^{8}$. La reforma de 1999

${ }^{5}$ Ley 25/1970, de 2 de diciembre, de Estatuto de la Viña, del Vino y de los Alcoholes.

${ }^{6}$ En la campaña 1985/86 España tenía un total de 1.516 .702 hectáreas de viñedo de uva para vinificación y contaba con 27 Denominaciones de Origen de vinos de calidad, con una superficie inscrita en ellas de 487.714 hectáreas, el 32,2\% del total del viñedo español.

7 La OCM vitivinícola ha tenido sucesivas normas que la regulaban: Reglamento $\mathrm{n}^{\mathrm{o}} 24 \mathrm{del}$ Consejo, sobre el establecimiento progresivo de una Organización Común del Mercado Vitivinícola (Diario Oficial $n^{\circ} 30$, de 20 de abril de 1962); Reglamento (CEE) no 337/79 del Consejo, de 5 de febrero de 1979, por el que se establece la Organización Común del Mercado Vitivinícola; Reglamento (CEE) n ${ }^{\circ}$ 822/87 del Consejo, de 16 de marzo de 1987, por el que se establece la Organización Común del Mercado Vitivinícola; Reglamento (CE) n n 1493/1999 del Consejo, de 17 de mayo de 1999, por el que se establece la Organización Común del Mercado Vitivinícola; y, Reglamento (CE) n n $^{\circ} 79 / 2008$ del Consejo, de 29 de abril de 2008, por el que se establece la Organización Común del Mercado Vitivinícola, se modifican los Reglamentos (CE) $\mathrm{n}^{\circ} 1493 / 1999$, (CE) $\mathrm{n}^{\mathrm{o}} 1782 / 2003$, (CE) $\mathrm{n}^{\circ} 1290 / 2005$ y (CE) $\mathrm{n}^{\circ} 3 / 2008$ y se derogan los Reglamentos (CEE) n $n^{\circ} 2392 / 86$ y (CE) no $1493 / 1999$.

${ }^{8}$ Puede consultarse a este respecto el Reglamento (CEE) $n^{\circ} 777 / 85$ del Consejo, de 26 de marzo de 1985, relativo a la concesión, para las campañas vitivinícolas 1985/86 a 1989/90, de primas por abandono definitivo de determinadas superficies plantadas de vid y el Reglamento (CEE) $\mathrm{n}^{\mathrm{o}}$ 1442/88 del Consejo, de 24 de mayo de 1988, sobre la concesión, para las campañas vitivinícolas de 1988/89 a 1995/96, de primas por abandono definitivo de superficies vitícolas. 
tuvo como objetivo alcanzar un mayor equilibrio entre la oferta y la demanda en el contexto de la liberalización del comercio internacional, como consecuencia de los acuerdos de la Ronda Uruguay en el Acuerdo General sobre Aranceles y Comercio (GATT), para lo que se financió la reestructuración de una parte importante del viñedo. No obstante, los excedentes de vino seguían siendo elevados y su eliminación suponía un gasto considerable. Finalmente, en 2008, se aprobó una nueva reglamentación que incluía una serie de medidas de apoyo $\mathrm{y}$ un conjunto de normas que regulan los intercambios comerciales con terceros países y el potencial productivo del sector.

El análisis de la evolución del viñedo español desde la entrada en la Comunidad Económica Europea hasta hoy muestra que la superficie plantada ha disminuido sensiblemente. A finales de 2008 había en España 1.088.334 hectáreas de viñedo de uva para vinificación, lo que supone una reducción del $28,2 \%$ en relación con la superficie plantada en 1985 . No obstante, este dato será aún mayor cuando se cuantifique definitivamente la superficie arrancada a lo largo de las campañas 2008/2009, 2009/2010 y 2010/2011, dentro del régimen de abandono de viñedo recogido en la actual $\mathrm{OCM}^{9}$, en la que se establecen las normas que regulan la atribución de fondos comunitarios a los Estados Miembros y su utilización por éstos a través de programas nacionales de apoyo para financiar medidas específicas destinadas al sector vitivinícola. A pesar del impacto socioeconómico de estas medidas en el medio rural, por la influencia que tiene la vitivinicultura y todas las actividades que se han ido desarrollando a su alrededor en las zonas donde el viñedo está asentado, a través de estos programas nacionales no se concede apoyo a las medidas recogidas en los Programas de Desarrollo Rural ${ }^{10}$, al objeto de que sean compatibles con la

9 El Reglamento (CE) n $n^{\circ} 491 / 2009$ del Consejo, de 25 de mayo de 2009, que modifica el Reglamento (CE) n $\mathrm{n}^{\mathrm{0}}$ 1234/2007 por el que se crea una Organización Común de Mercados Agrícolas y se establecen disposiciones específicas para determinados productos agrícolas, integra el sector vitivinícola en el Reglamento único para las OCM. Su aprobación obedece a la necesidad de incluir en él la reforma del mercado vitivinícola aprobada en 2008.

${ }^{10}$ Los Programas de Desarrollo Rural (PDR) para el periodo 2007-2013 están regulados en el Reglamento (CE) n $n^{\circ}$ 1698/2005 del Consejo, de 20 de septiembre de 2005, relativo a la ayuda al desarrollo rural a través del Fondo Europeo Agrícola de Desarrollo Rural (FEADER). Posteriormente, se aprobó el Reglamento (CE) no 473/2009 del Consejo, de 25 de mayo de 2009, que modifica el Reglamento (CE) $\mathrm{n}^{\circ}$ 1698/2005 relativo a la ayuda al desarrollo rural a través del Fondo Europeo Agrícola de Desarrollo Rural (FEADER) y el Reglamento (CE) $n^{\circ}$ 1290/2005 sobre la financiación de la política agrícola común, para dar cabida a los "nuevos retos": cambio climático, energías renovables, gestión del agua, biodiversidad, medidas de acompañamiento de la reestructuración del sector lechero, innovación vinculada a los cuatro primeros ámbitos anteriores y desarrollo de la infraestructura de internet de banda ancha en las zonas rurales. En el conjunto de la Unión Europea existen, para el período 2007-2013, 89 Programas de Desarrollo Rural que se están ejecutando en estos momentos. España cuenta con 17 PDRs, uno por cada Comunidad Autónoma, más un Programa que corresponde a la Red Rural Nacional. 
normativa comunitaria y coherentes con las actividades, políticas y prioridades de la Unión Europea, evitando duplicidades y garantizando la complementariedad.

Para dar cumplimiento a esta nueva reglamentación, España aprobó, el 27 de febrero de 2009, su Programa de Apoyo al Sector Vitivinícola Español ${ }^{11}$, que recoge las cinco medidas siguientes de las once posibles que proponía el Reglamento (CE) n $n^{\circ}$ 479/2008 del Consejo:

1. Promoción en mercados de terceros países. Pueden ser objeto de promoción los productos de calidad, destinados al consumo directo, que cuenten con posibilidades de exportación o de nuevas salidas comerciales en terceros países y que pertenezcan a alguna de las siguientes categorías:

- Vinos con Denominación de Origen Protegida (DOP).

- Vinos con Indicación Geográfica Protegida (IGP).

- Vinos en los que se indique la variedad de uva de vinificación.

2. Reestructuración y reconversión de viñedos. El apoyo sólo puede concederse para una o varias de las actividades siguientes:

- Reconversión varietal.

- Reimplantación de viñedos.

- Mejora de las técnicas de gestión de viñedos.

3. Eliminación de subproductos. Los productores están obligados a la eliminación de los subproductos obtenidos en la transformación. No obstante, aquéllos que en la campaña vitícola que se trate no produzcan más de 25 hectolitros de vino o mosto en sus instalaciones están exentos de esta obligación. Además, se concede una ayuda a los destiladores autorizados que transformen los subproductos obtenidos en territorio nacional entregados para su destilación en alcohol bruto con un grado alcohólico mínimo del 92\% Vol. Ahora bien, el alcohol obtenido de la destilación de subproductos por el que se haya concedido una ayuda se debe utilizar exclusivamente con fines industriales o energéticos con el fin de evitar distorsiones en la libre competencia.

4. Destilación de alcohol para uso de boca para las campañas 2008/09 y 2009/10.

5. Ayuda a la destilación de crisis en situaciones de excepcional desequilibrio del mercado causado por excedentes importantes o por problemas de calidad. El alcohol así obtenido deberá dirigirse sólo a usos industriales o energéticos.

${ }^{11}$ Real Decreto 244/2009, de 27 de febrero, para la aplicación de las medidas del Programa de Apoyo al Sector Vitivinícola Español. 
La dotación presupuestaria anual asignada al sector vitivinícola español para llevar a cabo estas actuaciones se presenta en el Gráfico 1.

\section{Gráfico 1}

Presupuesto del Programa de Apoyo al Sector Vitivinícola Español (Millones de euros)

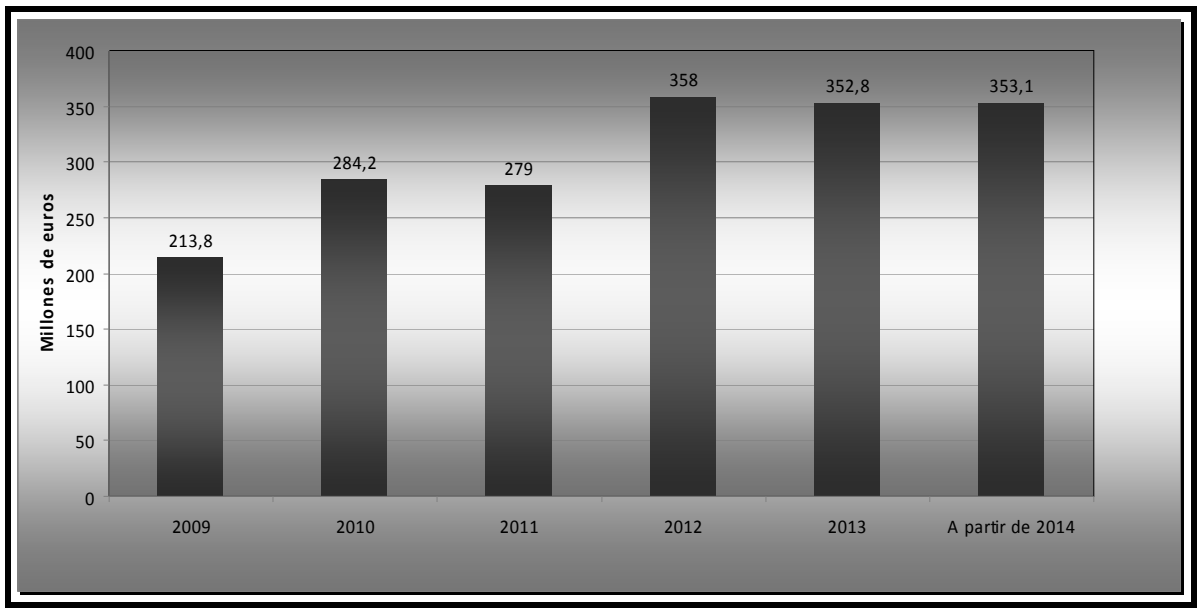

Fuente: Elaboración propia a partir del Reglamento (CE) n 491/2009 del Consejo, de 25 de mayo de 2009.

Como ha podido comprobarse, el sector vitivinícola europeo, y por ende el español, se halla muy intervenido, principalmente en lo que se refiere a la limitación de la superficie de viñedo y de la producción de uva así como a la obligación de contribuir a la eliminación de excedentes, aunque, también hay que considerar la intervención en forma de diversas ayudas que el sector recibe. En 2009, el sector español de "vinos y alcoholes" recibió ayudas por un montante total de 467,2 millones de euros ${ }^{12}$ (el 7,1\% de los pagos realizados por el Fondo Europeo Agrícola de Garantía ${ }^{13}$ (FEAGA)), destinados principalmente

${ }^{12}$ Resolución de 23 de agosto de 2010, del Fondo Español de Garantía Agraria (FEGA), por la que se publican las cuentas anuales del ejercicio 2009.

${ }^{13}$ El Fondo Europeo Agrícola de Garantía (FEAGA) se crea en 2005 y financia únicamente el primer pilar de política agrícola clásica. En gestión compartida con los Estados Miembros financia: las restituciones fijadas por exportación de productos agrícolas a terceros países; las intervenciones destinadas a la regularización de los mercados agrarios; los pagos directos a los agricultores establecidos en el ámbito de la política agrícola común; la contribución financiera de la Comunidad para medidas de información y promoción de los productos agrícolas en el mercado interior y en terceros países realizadas por mediación de los Estados Miembros y basadas en los programas aprobados por la Comisión; las ayudas a la reestructuración y para la diversificación establecidas en el sector del azúcar; y, la participación financiera de la Unión Europea en el plan de consumo de fruta en las escuelas. Asimismo, financia de modo centralizado: la participación financiera de la Comunidad en medidas veterinarias específicas, 
a ayudas a la destilación. Esta limitación implica que no se puede plantar una determinada superficie de viñedo de uva para vinificación sin tener previamente un derecho de plantación por una superficie equivalente. Los enormes excedentes europeos de vino, mosto y alcohol, y la característica de que es un cultivo en el que se tarda aproximadamente cinco años en alcanzar la plena producción, hicieron limitar la superficie de plantación, tal y como se señaló anteriormente. No obstante, esta limitación de plantación desaparecerá en 2015 o 2018, según los casos, y el futuro del sector ante esta liberalización se plantea con incertidumbre, habiéndose posicionado a favor de la eliminación de los derechos de plantación Bulgaria, Reino Unido, Países Bajos, Malta, Estonia, Suecia, Finlandia y España.

Desde nuestro punto de vista, la postura de España resulta incomprensible, porque no parece arriesgado aventurar que una liberalización del cultivo hará que, tanto viticultores como personas ajenas al sector, comiencen a plantar viñas en las regiones con mayor y mejor tradición vitícola, en las Denominaciones de Origen con vinos de mayor calidad debido a su ubicación, al buen hacer que a lo largo de décadas llevan realizando sus vitivinicultores y a las enormes inversiones llevadas a cabo en estas zonas durante años. En un plazo de 4 o 5 años a partir de la liberalización, y una vez entren en plena producción las viñas plantadas, es muy probable que nos encontremos ante un mercado en el que la producción de vino de Rioja, Ribera del Duero, Jerez, y tantas otras denominaciones de calidad y enorme prestigio, se dispare, con el consiguiente hundimiento de precios y, como resultado, la calidad se resienta ante la ausencia de los tradicionales elementos de control. Un mercado excedentario y con sus figuras de calidad deterioradas no parece la mejor forma de defender al sector vitivinícola.

Otro elemento significativo que caracteriza al sector es la apuesta que las distintas Administraciones han hecho en los últimos años por la calidad. Esto se refleja en las 83 Denominaciones de Origen Protegidas (DOP) y en las 43 Indicaciones Geográficas Protegidas (IGP) que existen actualmente en España en el ámbito vitivinícola. La Unión Europea ${ }^{14}$ engloba dentro de las $D O P$ a las

de control veterinario y de los productos destinados a la alimentación humana y animal; programas de erradicación y vigilancia de las enfermedades animales y medidas fitosanitarias; la promoción de productos agrícolas efectuada directamente por la Comisión o por mediación de organizaciones internacionales; las medidas destinadas a garantizar la conservación, la caracterización, la recogida y la utilización de recursos genéticos en agricultura; la creación y mantenimiento de los sistemas de información contable agraria; los sistemas de investigación agraria; y, los gastos relativos a los mercados de la pesca.

${ }^{14}$ Reglamento (CE) n ${ }^{\circ}$ 607/2009 de la Comisión, de 14 de julio de 2009, por el que se establecen determinadas disposiciones de aplicación del Reglamento (CE) no 479/2008 del Consejo en lo que atañe a las denominaciones de origen e indicaciones geográficas protegidas, a los términos tradicionales, al etiquetado y a la presentación de determinados productos vitivinícolas. 
Denominaciones de Origen y a los Vinos de Calidad con Indicación Geográfica e incluye dentro de las IGP a los Vinos de la Tierra. Con una superficie de 637.468 hectáreas de viñedo inscrito en alguna DOP en España, el 58,6\% del total del viñedo español, se puede afirmar que la evolución del viñedo en su apuesta por la calidad en los últimos veinticinco años ha sido espectacular ${ }^{15}$.

Pero también ha habido actuaciones polémicas en esta materia como es el caso de la creación de la marca "Viñedos de España", para los vinos con derecho a la mención tradicional Vino de la Tierra, producidos en ciertas zonas geográficas, que excluía los viñedos de Galicia, Asturias, Cantabria, País Vasco, Castilla y León y La Rioja ${ }^{16}$. ¿Alguien se podría imaginar encontrar en cualquier establecimiento comercial una botella de vino francés, por ejemplo, bajo la marca "Viñedos de Francia" y cuyo origen fuera un vino de mesa? ¿Cómo cuantificar el daño que se haría a la política de promoción de los caldos franceses de calidad desarrollada durante décadas, a regiones vitícolas como Burdeos, Borgoña o Champagne, si se asociara una hipotética marca "Viñedos de Francia" o similar con vinos de calidad cuestionable? ${ }^{17}$ En un mundo tan

${ }^{15}$ Véase a este respecto el comentario que se recoge en la nota a pie de página 5.

${ }^{16}$ En 2006 se creó esta marca mediante la Orden APA/2535/2006, de 27 de julio, por la que se reconoce y regula la Indicación Geográfica «Viñedos de España» para los vinos con derecho a la mención tradicional «Vino de la Tierra» producidos en la zona geográfica que se delimita, y fue anulada por la Audiencia Nacional mediante Sentencia de 2 de julio de 2008, por no ser conforme a Derecho. Tres años después, el Ministerio, en su empeño por sacar adelante la marca, aprobó la Orden ARM/2067/2009, de 29 de julio, por la que se reconoce y regula la Indicación Geográfica "Viñedos de España" para los vinos con derecho a la mención tradicional "Vino de la Tierra" producidos en la zona geográfica que se delimita, con características similares a la de 2006. Las Comunidades Autónomas de La Rioja y Castilla y León mostraron su oposición a dicha Orden, que también fue objeto de recurso contenciosoadministrativo por parte de la organización Unión de Uniones de Agricultores y Ganaderos, que no ha llegado a resolverse antes de la derogación de la Orden y, por tanto, de la eliminación de la marca "Viñedos de España" mediante la reciente aprobación de la Orden ARM/313/2011, de 9 de febrero, por la que se deroga la Orden ARM/2067/2009, de 29 de julio, tras las advertencias de la Comisión Europea a mediados de 2010.

${ }^{17}$ Sin embargo, no es ésta una polémica nueva y España sabe bien de ello. Durante la década de los ochenta y primeros años de los noventa, la Denominación de Origen Jerez, Sherry o Xérès y Manzanilla de Sanlúcar de Barrameda sufrió la competencia "desleal" del British Sherry (ahora fortified wine), que se tradujo en importantes pérdidas de cuota de mercado para este vino español, principalmente debido al bajo precio del inglés. Esta diferencia de precios se derivó de un diferencial del tipo impositivo sobre el alcohol distinto para ambos productos: mientras el precio de una botella de Jerez oscilaba entre las 5 y las 7 libras, el de una botella de British Sherry se movía en el entorno de las 4 libras. Los consumidores, influenciados por el precio y la similitud de la denominación, así como por su falta de capacidad de diferenciación, demandaron British Sherry provocando una importante reducción de las exportaciones españolas de Jerez. Este hecho dio lugar a que España presentara una demanda judicial contra Reino Unido ante el Tribunal de Justicia de las Comunidades Europeas, el 4 de septiembre de 1992, resolviéndose el litigio mediante el acuerdo de armonización de tipos impositivos y no utilización de la denominación British Sherry a partir del 1 de enero de 1996. 
globalizado como el actual y en un mercado tan maduro como el del vino, todo lo que no sea apostar por la calidad y por la excelencia está abocado al fracaso.

Desde el Ministerio de Medio Ambiente y Medio Rural y Marino (MARM) se ha puesto en marcha la Estrategia Vino 2010, que nació con el propósito de implicar a todos los operadores del sector hacia la consecución de objetivos comunes, en los que la competitividad y la calidad ocupaban un lugar destacado. La estrategia se basa en cuatro ejes que abarcan los siguientes ámbitos de actuación:

-Eje 1: Competitividad, que trata de fomentar en los operadores del sector los elementos mínimos imprescindibles para ser competitivos en el mercado mundial del vino.

-Eje 2: Profesionalización, para apoyar las iniciativas de profesionalización que aportan ventajas competitivas al vino español.

- Eje 3: Consumidores, que busca vertebrar las actuaciones del sistema vitivinícola español para adecuarse a las demandas de los consumidores.

- Eje 4: Emprendedores, para promover nuevos proyectos de emprendedores vitivinícolas en los mercados interior y exterior que contribuyan al liderazgo mundial del vino español.

Ahora bien, esta apuesta por la mejora de los viñedos y la calidad de las uvas no tendría sentido sin una dinámica industria transformadora ${ }^{18}$ y unos potentes canales de distribución y comercialización. Según datos del Ministerio de Medio Ambiente y Medio Rural y Marino, las ventas netas de vino en España en el año $2007^{19}$ supusieron un total de 5.291 millones de euros (lo que representa el $6,4 \%$ de las ventas netas del conjunto de la industria agroalimentaria española); en ese mismo año, la industria vinícola daba empleo a 23.495 personas (el $6,2 \%$ de las personas ocupadas en este sector) y aportaba un valor añadido de 1.609 millones de euros (el $8 \%$ del total generado por la industria agroalimentaria nacional).

En determinadas comarcas de España el viñedo es la base de la economía local. Aunque la producción de uva y la elaboración de vino es la actividad económica principal, no es la única; hay otras muchas que dependen directamente de ella, como la industria de fabricación de maquinaria, elaboración de corcho, tonelería, botellas, etiquetas, logística,..., y otras

${ }^{18}$ En la campaña 2008/2009 se produjeron en España un total de 34,4 millones de hectolitros de vino, de los cuales 21,5 millones correspondían a vino de mesa, 12,3 millones a vinos calificados como Vino de Calidad Producido en una Región Determinada (vcprd), y 0,6 millones a otros vinos. A estas cifras habría que añadir 5,8 millones de mosto y 0,1 millones de zumo de uva.

19 Último dato disponible publicado en el Anuario de Estadística 2009 del MARM (última actualización el 13 de diciembre de 2010). 
actividades que surgen al amparo del vino y que lo complementan y diversifican, tales como el enoturismo o la gastronomía, sin considerar la producción de otros bienes intangibles como la conservación del paisaje, el freno a la erosión o la fijación de la población en el medio rural. El viñedo y la industria vinícola son, por tanto, un sector vital en muchas zonas de España y su cuidado y fomento deben guiar las decisiones de todas las Administraciones. Habrá que esperar a 2015 o 2018, según los casos, para conocer el efecto de la liberalización si es que al final ésta se produce, dado que, en los últimos meses, mandatarios europeos tan influyentes como Nicolás Sarkozy o Angela Merkel se han pronunciado a favor de revisar la OCM para evitar la liberalización de los derechos de replantación de viñedo a partir de esas fechas.

\section{VINO Y DESARROLLO RURAL: ENOTURISMO Y "VINNOVACIÓN" "0}

El interés que está despertando en los últimos años el vino y todo lo que gira a su alrededor obedece a cuestiones relacionadas con aspectos culturales, gastronómicos y de salud ${ }^{21}$, debido, en este último caso, a los beneficios que puede reportar al organismo su consumo moderado. Pero el vino es también la espina dorsal de la economía de amplias zonas rurales de la Unión Europea, del que dependen un gran número de empleos, con fuertes efectos de arrastre "hacia atrás” y "hacia delante" y con repercusiones sobre el medio ambiente, la tecnología y la innovación. La fuerte competencia existente dentro del sector, dado que todas las empresas luchan por satisfacer un mercado cada vez más exigente en precio y en calidad, ha derivado en una apuesta por la innovación de todo tipo ${ }^{22}$, compaginando "lo nuevo" con la esencia de la tradición vinícola más arraigada, lo que está permitiendo a muchas bodegas no sólo mantener su cuota de mercado sino incrementarla, gracias a la diversificación de su

20 Vocablo original de los autores para denominar la innovación en el mundo del vino y la viticultura.

${ }^{21}$ Son numerosos los estudios que demuestran que el consumo moderado de vino tiene algunos beneficios concretos para la salud. Así, se ha comprobado que algunos componentes del vino son efectivos contra la bacteria Helicobacter pylori, que una cantidad moderada en enfermos con esteatosis hepática no alcohólica (ESNA) reduce la cantidad de grasa en el hígado o que componentes como el resveratrol protege el sistema cardiovascular y reduce la oxidación celular.

${ }^{22}$ Hace prácticamente un siglo, en 1912, Joseph Alais Schumpeter publicaba su obra Theory of Economic Development, en la que distingue los siguientes tipos de innovación: la introducción de un nuevo producto, o de una nueva característica en un producto, con el que los consumidores no estén familiarizados (innovación de producto); la aparición de un nuevo método de producción (innovación de proceso); la aplicación de nuevas formas de organización; la apertura de un nuevo mercado en el que la empresa o rama de actividad no hubiera entrado todavía; y, el empleo de una nueva fuente de materias primas, de factores de producción o de productos intermedios. 
producción que les ha llevado a introducirse en ámbitos tan variados como los de la cosmética, el vino sin alcohol o el enoturismo ${ }^{23}$.

El enoturismo, o lo que es lo mismo, el desarrollo de actividades turísticas, de ocio y tiempo libre dedicadas al descubrimiento y disfrute cultural y enológico de la viña, el vino y su territorio, ha experimentado un fuerte impulso en los últimos años. En muchos países el vino es simultáneamente la expresión de la cultura de un territorio y un cúmulo de tradiciones ancestrales que identifican a una comunidad local. Como afirman Asero y Patti (2009), el vino, al igual que otros muchos productos típicos, puede definirse como un "producto intensivo en territorio" (PIT), dado que contiene un elevado componente territorial referido al lugar en el que se produce, de manera que vino y territorio se representan recíprocamente. Por ello, prácticamente en todas las regiones vitivinícolas del mundo se han desarrollado o se están iniciando políticas que promueven el enoturismo en sus respectivas áreas de influencia. Entre las zonas pioneras más importantes destacan: los Valles de $\mathrm{Napa}^{24}$ y de Sonoma ${ }^{25}$, ambas en California; y las regiones de Alsacia ${ }^{26}$ y Burdeos ${ }^{27}$, en Francia. Ellas son el espejo en el que comenzaron a mirarse todas las comarcas vitícolas que deseaban implantar un modelo de turismo sostenible basado en el mundo del vino. En Europa, conscientes del potencial que el enoturismo tenía y el éxito alcanzado por las primeras Rutas del Vino que se pusieron en marcha, se creó la

${ }^{23}$ Es el caso del Grupo Matarromera, cuya sede central se ubica en el término municipal de Valbuena de Duero en la provincia de Valladolid, pionero en el desarrollo de un nuevo producto: el vino sin alcohol. Obtuvo en 2010 una cifra de negocio de 14,9 millones de euros y las previsiones de la empresa para 2015 estiman que el $40 \%$ de sus ventas proceda del vino sin alcohol, un $50 \%$ de los vinos normales de sus siete bodegas, que abarcan las cuatro Denominaciones de Origen bañadas por el Duero (Ribera del Duero, Rueda, Cigales y Toro), y un $10 \%$ del resto de sus líneas de producto: enoturismo, aceite de oliva virgen y cosméticos. En 2010 abrió dos filiales: Matarromera China, con sede en Shanghai y Matarromera USA, en Nueva York, con el objetivo de satisfacer las buenas expectativas de crecimiento de estos dos importantes mercados.

${ }^{24}$ En 2005, último dato disponible, recibió alrededor de 4,7 millones de turistas, con un gasto medio diario de 129 euros. El impacto del enoturismo sobre la economía local ascendió a 1.300 millones de dólares, generando un total de 17.500 empleos.

25 Alrededor de 7 millones de visitas, en 2008, que generaron unos ingresos de 750 millones de euros. El impacto sobre el empleo también es importante, pues trabajan en el sector alrededor de 15.500 personas.

${ }^{26}$ En 2009 visitaron esta región algo más de 2 millones de personas alcanzándose los 5 millones de pernoctaciones. El enoturismo genera alrededor de 3.600 empleos en Alsacia, lo que representa un $13 \%$ del total regional.

${ }^{27}$ En 2009 recibió un total de 5,8 millones de turistas, de los cuales el 70\% pernoctó en la región, dado que ésta tiene una amplia oferta enoturística de elevada calidad y variedad, así como actividades complementarias que hacen que un elevado porcentaje de visitantes opten por alargar su estancia en la zona en lugar de realizar una simple visita de duración inferior a un día. 
Red Europea de las Ciudades del Vino ${ }^{28}$ (RECEVIN) como asociación sin ánimo de lucro con sede en Estrasburgo.

A esta Red pueden adherirse las ciudades o grupos de ciudades europeas, tanto pertenecientes a los Estados Miembros de la Unión Europea como de terceros países, siempre que se encuentren en una zona de producción vinícola protegida por una denominación de calidad, fuertemente relacionada, tanto económica como culturalmente, a la vitivinicultura y tengan más de 5.000 habitantes (las ciudades con un número inferior pueden adherirse de forma asociada). No pueden formar parte de la Red las ciudades que no se hayan adherido previamente a la asociación nacional del propio país, en el caso de que ésta exista. Actualmente, pertenecen a esta Red Europea ciudades de Alemania, Austria, Eslovenia, España, Francia, Grecia, Hungría, Italia y Portugal. Todas ellas se comprometen a desarrollar actuaciones encaminadas a:

- Promocionar la cultura del vino colaborando con el sector vitivinícola en la divulgación y el conocimiento de los productos de las diferentes $D O P$, la excelencia de los vinos y sus propiedades saludables, dado que la viña y el vino forman parte del patrimonio de Europa, que ha sido un elemento esencial para el desarrollo económico, social y cultural de las distintas zonas vitivinícolas, incidiendo en la importancia del terruño y los orígenes, y difundiendo las características organolépticas de un producto que está relacionado íntimamente con la gastronomía.

- Actuar como lobby mediante el desarrollo de posicionamientos de interés común a escala europea de todas las ciudades del vino, tanto en lo que se refiere a cuestiones fundamentales para el sector vitivinícola como para las

${ }^{28}$ Según se establece en el artículo 2 de sus Estatutos, la Red persigue los siguientes objetivos: promocionar la viticultura y las relaciones entre los territorios destinados a la producción de vinos de calidad a nivel internacional; construir Europa a través de la formación del ciudadano europeo, bajo el perfil cultural, social, profesional y económico; proteger, poner en valor y promocionar los territorios con vocación vitivinícola y agrícola, las actividades agroalimentarias, la producción de las especialidades enogastronómicas y las producciones de la economía compatibles con el medio ambiente, con el objetivo de asegurar la permanencia de los agricultores en el territorio; incentivar el desarrollo económico local mediante una oferta turística basada en el territorio, los productos y los servicios; promocionar el desarrollo de una moderna cultura empresarial eficiente y motivada gracias a la formación y el reciclaje de los conocimientos profesionales; valorizar los recursos naturales, históricos, culturales y medioambientales; crear servicios dirigidos a la información y a la innovación en el sector vinícola; promocionar iniciativas innovadoras, como la creación de redes de museos y de bodegas internacionales; realizar estudios y servicios dirigidos a la información que permitan un conocimiento reciproco e intercambios culturales entre las ciudades del vino miembros de la asociación y entre éstas y otras ciudades incluso extracomunitarias; publicar revistas, material promocional y divulgativo; y, buscar financiación para proyectos transnacionales. Puede encontrarse más información en: www.recevin.net. 
propias ciudades en aspectos relacionados con el desarrollo local/rural.

- Fomentar el enoturismo integrando bajo un mismo concepto temático los recursos y servicios turísticos de interés, existentes y potenciales, de las distintas zonas vitivinícolas. Con este objetivo se han desarrollado los dos proyectos siguientes:

1. La acreditación de las Rutas del Vino Europeas, aplicando el Vademécum del Enoturismo Europeo, fruto del proyecto INTERREG IIIC Vintur (2004-2006), como marca europea del enoturismo. Uno de los resultados de este proyecto fue la aprobación de la Carta Europea del Enoturismo, tras el acuerdo entre diferentes Administraciones Públicas y operadores privados del sector, representados por RECEVIN, y la Asamblea de Regiones Europeas del Vino (AREV). Esta Carta compromete a todos los firmantes a establecer una estrategia en el ámbito local a favor de un desarrollo enoturístico sostenible; es decir, una forma de desarrollo de la actividad enoturística que respete y preserve los recursos naturales, culturales y sociales y que contribuya al desarrollo económico y social de los territorios adheridos ${ }^{29}$.

2. La creación del Día Europeo del Enoturismo que se celebra, desde 2009 , el segundo domingo de noviembre en cada una de las ciudades pertenecientes a la Red.

- Proporcionar formación a jóvenes viticultores y a estudiantes de enología, con edades comprendidas entre 18 y 35 años, complementándola con visitas guiadas a empresas vitivinícolas y catas.

Se pretende así consolidar una estrategia integrada de desarrollo a lo largo y ancho de las zonas vitivinícolas europeas.

\section{EL PRODUCTO RUTAS DEL VINO DE ESPAÑA: UNA ESTRATEGIA INTEGRADA DE DESARROLLO RURAL}

La principal fórmula para organizar el enoturismo es la de crear itinerarios o rutas integradas por zonas productoras de vino de calidad que ofrecen al turista la oportunidad de conocer los recursos naturales, históricos y culturales que caracterizan los territorios visitados. Esta fórmula ha sido ampliamente desarrollada en distintos países como se pone de manifiesto en diferentes

${ }^{29}$ Adherirse a la Carta Europea del Enoturismo implica realizar un diagnóstico de la situación, fomentar y considerar la participación de los socios, establecer objetivos estratégicos comunes, asignar los medios necesarios para su consecución, ejecutar un programa para alcanzarlos y realizar una evaluación posterior de los resultados obtenidos. Para ello, se divide el sistema enoturístico en dos grandes áreas, cada una compuesta por un conjunto específico de compromisos: i) el territorio o las entidades que tengan competencias en su planificación y gestión, y ii) la empresa vitivinícola y aquellas otras que presten servicios enoturísticos. 
estudios que analizan experiencias en Europa (Hall et al., 2000), Sudáfrica (Bruwer, 2003) o Australia (Charters y Ali-Knight, 2002).

Estas rutas se identifican con entidades socio-territoriales que pueden considerarse una variante del modelo de distrito industrial ${ }^{30}$, dado que cada ruta se caracteriza por "la presencia activa tanto de una comunidad abierta de personas, como de un conjunto de pequeñas y medianas empresas, en una zona natural e históricamente determinada, en la que comunidad y empresas tienden a fundirse" ${ }^{31}$ (Becattini, 2005, p.17).

Tomando como base teórica el concepto de distrito industrial marshalliano y sabiendo que el vino puede utilizarse como recurso para generar un flujo de visitantes que desean descubrir no sólo el origen del producto en sí mismo, sino también conocer los lugares y los modos de producción, se han creado en España la Asociación Española de Pequeñas y Medianas Ciudades Vitivinícolas (ACEVIN) y las Rutas del Vino de España.

\subsection{La Asociación Española de Pequeñas y Medianas Ciudades Vitivinícolas (ACEVIN)}

La importancia del sector vitivinícola español, junto con la diversidad y calidad de los destinos turísticos españoles, hacen de España un país idóneo para el desarrollo del enoturismo. Con estas mimbres nace, en 1994, la Asociación Española de Pequeñas y Medianas Ciudades Vitivinícolas (ACEVIN), con sede en Alcázar de San Juan (Ciudad Real), como una entidad sin ánimo de lucro que persigue objetivos similares a los de la Red Europea ${ }^{32}$.

${ }^{30} \mathrm{El}$ concepto de distrito industrial fue utilizado por Alfred Marshall en sus obras The Economics of Industry (con su esposa Mary Peley, publicada en 1879), Principles of Economics (1890) e Industry and Trade, editada en 1919, para designar la implantación de un grupo de empresas en un área geográfica e históricamente determinada.

${ }^{31}$ Puede consultarse en relación con este tema el artículo "El distrito industrial marshalliano", que se recoge en: Pyke, F.; Becattini, G. y Sengenberger, W. (1992): Los distritos industriales y las pequeñas empresas I. Distritos industriales y cooperación interempresarial en Italia, que publicó el Ministerio de Trabajo y Seguridad Social, como versión española del original: Industrial districts and interfirm cooperation in Italy, publicado en 1990 por el Instituto Internacional de Estudios Laborales en Ginebra.

32 Entre ellos: colaborar en las acciones concretas que tengan por finalidad el desarrollo y la diversificación económica de sus socios; promover y facilitar las adaptaciones e iniciativas que sean necesarias para incrementar la competitividad de la industria vitivinícola y mantener e incrementar el nivel de bienestar económico y social de las ciudades miembros; promover todas las formas de intercambio cultural, científico, tecnológico y económico entre los municipios de la asociación; estimular todas las relaciones y los intercambios entre las diferentes ciudades miembros en aquellos ámbitos de interés coincidentes y entre éstas y otras instituciones y empresas especialmente relacionadas con la producción y comercialización vitivinícola; definir una nueva estrategia en el ámbito de la formación profesional y del 
Pueden pertenecer a ACEVIN todos aquellos municipios, mancomunidades o asociaciones de municipios pertenecientes al ámbito geográfico de una Denominación de Origen vitivinícola cuya actividad económica relacionada con la agroindustria del vino, en el territorio representado por el ente local, sea predominante sobre las restantes actividades, y que el grado de dependencia de su riqueza industrial o comercial, respecto a esta actividad, se considere importante para el desarrollo equilibrado de la población. Asimismo, pueden ser socios todas las personas jurídicas que estén vinculadas a la viticultura y contribuyan a los fines de esta Asociación. Desde su creación, distintas Administraciones Públicas y Asociaciones se han ido adhiriendo progresivamente a ésta (Tabla 1).

Tabla 1

Relación de Administraciones Públicas y Asociaciones pertenecientes a ACEVIN

\begin{tabular}{|c|c|c|}
\hline Provincia & Administraciones Públicas & Asociaciones \\
\hline Álava & $\begin{array}{l}\text { Ayuntamiento de Laguardia } \\
\text { Diputación Foral de Álava }\end{array}$ & $\begin{array}{l}\text { Asociación para la Promoción del } \\
\text { Turismo y la Economía "Ruta del } \\
\text { Vino de la Rioja Alavesa" } \\
\text { Cuadrilla de Ayala }\end{array}$ \\
\hline Albacete & Ayuntamiento de Villarrobledo & \\
\hline Alicante & $\begin{array}{l}\text { Ayuntamiento de Pinoso } \\
\text { Ayuntamiento de Villena } \\
\text { Diputación Provincial de Alicante }\end{array}$ & \\
\hline Asturias & Ayuntamiento de Cangas de Narcea & \\
\hline Badajoz & $\begin{array}{l}\text { Ayuntamiento de Almendralejo } \\
\text { Ayuntamiento de Santa Marta de los Barros } \\
\text { Ayuntamiento de Villafranca de los Barros }\end{array}$ & \\
\hline Barcelona & $\begin{array}{l}\text { Ayuntamiento de Manresa } \\
\text { Ayuntamiento de Sant Sadurní DAnoia } \\
\text { Ayuntamiento de Vilafranca del Penedès }\end{array}$ & $\begin{array}{l}\text { Consorci de Promoció Turística de } \\
\text { I'Alt Penedès }\end{array}$ \\
\hline Burgos & $\begin{array}{l}\text { Ayuntamiento de Aranda de Duero } \\
\text { Ayuntamiento de Lerma } \\
\text { Diputación Provincial de Burgos }\end{array}$ & $\begin{array}{l}\text { Consorcio Ruta del Vino Ribera del } \\
\text { Duero }\end{array}$ \\
\hline Cádiz & $\begin{array}{l}\text { Ayuntamiento de Chiclana de la Frontera } \\
\text { Ayuntamiento de El Puerto de Santa María } \\
\text { Ayuntamiento de Jerez de la Frontera } \\
\text { Ayuntamiento de Rota } \\
\text { Ayuntamiento de Trebujena }\end{array}$ & $\begin{array}{l}\text { Asociación Rutas del Vino y del } \\
\text { Brandy del Marco de Jerez }\end{array}$ \\
\hline
\end{tabular}

mercado de trabajo, en el marco industrial, urbanístico, cultural y del medio ambiente; y, cooperar con las ciudades europeas del vino a través de RECEVIN. 
Tabla 1 (continuación)

Relación de Administraciones Públicas y Asociaciones pertenecientes a ACEVIN

\begin{tabular}{|c|c|c|}
\hline Provincia & Administraciones Públicas & Asociaciones \\
\hline $\begin{array}{l}\text { Ciudad } \\
\text { Real }\end{array}$ & $\begin{array}{l}\text { Ayuntamiento de Alcázar de San Juan } \\
\text { Ayuntamiento de Campo de Criptaza } \\
\text { Ayuntamiento de Daimiel } \\
\text { Ayuntamiento de Herencia } \\
\text { Ayuntamiento de Manzanares } \\
\text { Ayuntamiento de Pedro Muñoz } \\
\text { Ayuntamiento de Socuéllamos } \\
\text { Ayuntamiento de Tomelloso } \\
\text { Ayuntamiento de Valdepeñas } \\
\end{array}$ & $\begin{array}{l}\text { Asociación Ruta del Vino de La } \\
\text { Mancha }\end{array}$ \\
\hline Córdoba & $\begin{array}{l}\text { Ayuntamiento de Aguilar de la Frontera } \\
\text { Ayuntamiento de Lucena } \\
\text { Ayuntamiento de Montilla } \\
\text { Ayuntamiento de Moriles } \\
\end{array}$ & $\begin{array}{l}\text { Asociación para la Promoción del } \\
\text { Turismo del Vino }\end{array}$ \\
\hline Cuenca & Ayuntamiento de San Clemente & \\
\hline Huelva & Ayuntamiento de La Palma del Condado & $\begin{array}{l}\text { Mancomunidad de Desarrollo del } \\
\text { Condado de Huelva }\end{array}$ \\
\hline Huesca & Ayuntamiento de Barbastro & $\begin{array}{l}\text { Asociación para la Promoción } \\
\text { Turística del Somontano }\end{array}$ \\
\hline $\begin{array}{l}\text { Islas } \\
\text { Baleares }\end{array}$ & $\begin{array}{l}\text { Consejería de Turismo. Gobierno de } \\
\text { Baleares }\end{array}$ & \\
\hline La Rioja & Ayuntamiento de Logroño & $\begin{array}{l}\text { Mancomunidad de Ábalos, Briñas, } \\
\text { Briones y San Vicente de la } \\
\text { Sonsierra }\end{array}$ \\
\hline $\begin{array}{l}\text { Las } \\
\text { Palmas }\end{array}$ & $\begin{array}{l}\text { Ayuntamiento de San Bartolomé } \\
\text { Ayuntamiento de Tías }\end{array}$ & \\
\hline León & $\begin{array}{l}\text { Ayuntamiento de Cacabelos } \\
\text { Ayuntamiento de Gordoncillo }\end{array}$ & \\
\hline Lleida & Ayuntamiento de Lleida & \\
\hline Málaga & Ayuntamiento de Ronda & \\
\hline Murcia & $\begin{array}{l}\text { Ayuntamiento de Bullas } \\
\text { Ayuntamiento de Jumilla } \\
\text { Ayuntamiento de Yecla }\end{array}$ & $\begin{array}{l}\text { Asociación Ruta del Vino de Bullas } \\
\text { Asociación Ruta del Vino de Jumilla }\end{array}$ \\
\hline Navarra & $\begin{array}{l}\text { Ayuntamiento de Estella } \\
\text { Ayuntamiento de Olite } \\
\text { Ayuntamiento de Viana }\end{array}$ & $\begin{array}{l}\text { Grupo de Acción Local de la Zona } \\
\text { Media de Navarra }\end{array}$ \\
\hline Orense & Ayuntamiento de Ribadavia & Asociación Ruta do Viño do Ribeiro \\
\hline Pontevedra & Ayuntamiento de Cambados & $\begin{array}{l}\text { Asociación Ruta do Viño do Rias } \\
\text { Baixas }\end{array}$ \\
\hline Tarragona & Ayuntamiento de Falset & \\
\hline Tenerife & $\begin{array}{l}\text { Ayuntamiento de Icod de los Vinos } \\
\text { Ayuntamiento de Tacoronte }\end{array}$ & $\begin{array}{l}\text { Asociación Ruta del Vino de } \\
\text { Tenerife }\end{array}$ \\
\hline Toledo & Ayuntamiento de El Toboso & \\
\hline Valencia & $\begin{array}{l}\text { Ayuntamiento de Requena } \\
\text { Ayuntamiento de Utiel }\end{array}$ & $\begin{array}{l}\text { Asociación Ruta del Vino de la DO } \\
\text { Utiel-Requena }\end{array}$ \\
\hline Valladolid & $\begin{array}{l}\text { Ayuntamiento de Medina del Campo } \\
\text { Ayuntamiento de Peñafiel }\end{array}$ & Mancomunidad Tierras de Medina \\
\hline Zaragoza & Ayuntamiento de Cariñena & Comarca Campo de Borja \\
\hline
\end{tabular}

Fuente: Elaboración propia a partir de la información disponible en www.acevin.es. 
La estrategia de ACEVIN se centra en difundir la riqueza y las características propias de las zonas y ciudades donde la vitivinicultura ha sido históricamente, y sigue siendo en gran medida, la base de la economía local con el fin de potenciarla como motor de otras actividades económicas ${ }^{33}$, pues como ya se ha señalado, la industria vitivinícola actúa como input de actividades complementarias como el turismo (rutas del vino; hoteles y alojamientos; restauración y gastronomía; museos del vino; tiendas especializadas y pequeño comercio; publicidad;...) o la promoción del territorio (recuperación y rehabilitación del patrimonio arquitectónico, histórico, cultural y natural; folklore, tradiciones y fiestas populares; artesanía;...).

Ahora bien, debe asumirse que las expectativas del enoturista pueden variar en cada región, pero también el vino, que puede desempeñar un papel predominante, complementario, marginal o exclusivo en la oferta turística de un territorio, aunque en todos los casos se constituye como un factor de competitividad para cualquier destino (Asero y Patti, 2009). Más aún, puede afirmarse que el enoturismo tiene el potencial de generar una ventaja competitiva en las regiones vitivinicultoras. Lógicamente, cuanto más exclusivo sea el producto, mayores serán las oportunidades en el mercado. De manera que, dadas las características de este tipo de turismo y la heterogeneidad del enoturista que un territorio puede recibir, se hace necesaria su caracterización para segmentar la oferta, pudiendo clasificarlos en tres categorías diferentes (Gráfico 2):

- Turistas generales. Es el grupo más numeroso y practican el enoturismo de forma esporádica ya que la finalidad de su viaje es conocer la comarca, siendo la vitivinicultura un atractivo más. Sus conocimientos sobre el vino son limitados y necesita información y explicaciones sobre él.

- Turistas interesados en el vino y la región. El objetivo de su viaje se comparte entre el disfrute del vino y su cultura con otros atractivos de la comarca visitada. Su conocimiento del mundo del vino es elevado.

- Turistas enólogos. Dominan la enología y son apasionados de la cultura del vino. Descubrir el destino vitivinícola concreto es la motivación de su viaje.

${ }^{33}$ Para ello ha liderado la puesta en marcha de los siguientes proyectos: Vinadapt y Mipevin, que abarcan actuaciones de reciclaje y adaptación de trabajadores en activo, especialmente del sector vitivinícola; Bacche, que se centra en la investigación y formación en nuevas tecnologías en el sector vitivinícola; Yacimientos del Vino, que apoya la creación y puesta en marcha de iniciativas empresariales relacionadas con el turismo y la cultura del vino; Vintur, encaminado al desarrollo de estrategias y herramientas para el establecimiento de un modelo de enoturismo común a las ciudades y regiones del vino de Europa; y, Vinqual, que comprende un conjunto de actuaciones de reciclaje y adaptación de los empleados y empresas que integran las Rutas del Vino a los procesos de cambio generados por la oferta de nuevos servicios vinculados al turismo. 


\section{Gráfico 2}

Tipología y representatividad de los enoturistas

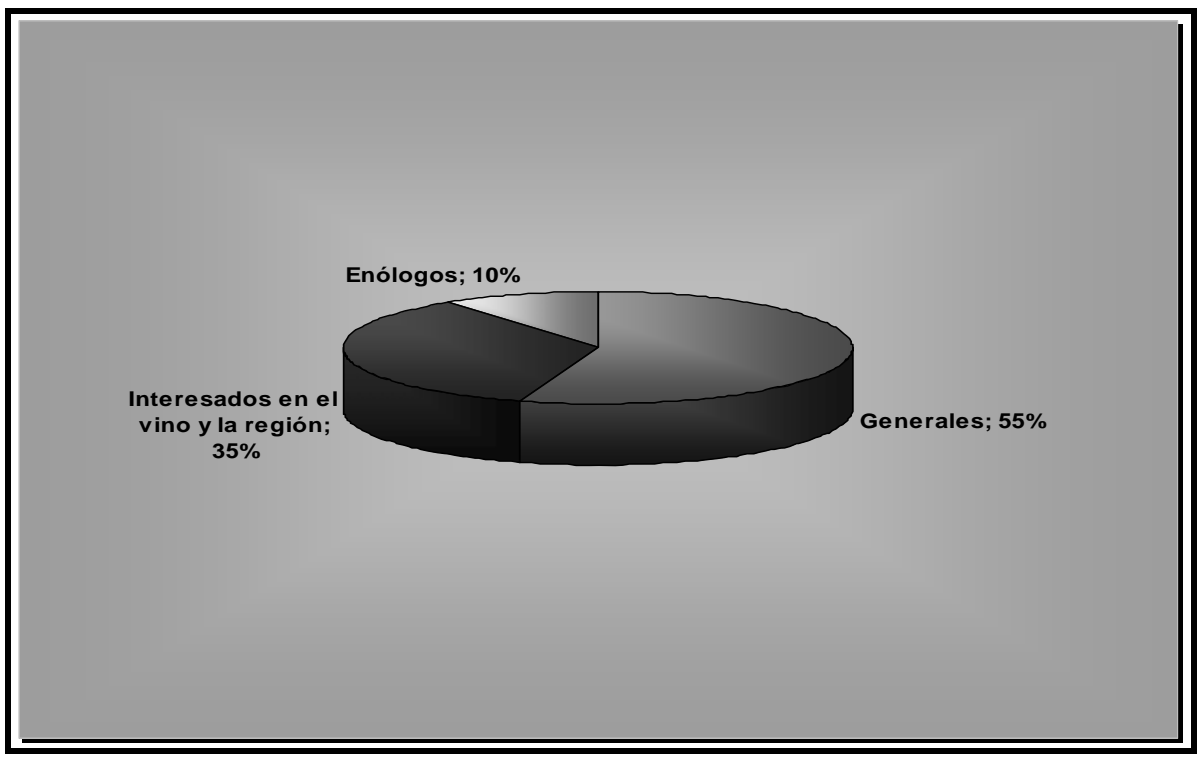

Fuente: Elaboración propia a partir de datos publicados por ACEVIN.

El enoturismo puede definirse de diferentes formas. Algunos autores lo han utilizado para referirse a las visitas a los viñedos, las bodegas y las fiestas de la vendimia, aunque el mayor factor de motivación para el visitante es la posibilidad de realizar catas y conocer los atractivos de la región vinícola en cuestión. Charters y Ali-Knight (2002) sugieren que el enoturismo abarca muchas posibilidades incluyendo la experiencia de un estilo de vida, educación, vínculos con el arte, enogastronomía, catas y ventas en bodegas, rutas guiadas, ..., permitiendo al visitante aprehender los valores económicos, sociales y culturales de un territorio. El producto Rutas del Vino de España ha sido diseñado para este fin.

\subsection{Las Rutas del Vino de España}

Una ruta del vino se identifica en el mercado por la imagen que transmite la identidad geográfica y el origen regional de un vino. La calidad de éste refuerza la imagen de los territorios contribuyendo al desarrollo económico local y a la promoción de la oferta turística. Pero para ello, es necesario que los stakeholders locales de una ruta configuren un sistema de relaciones entre bodegas, instituciones y todo tipo de empresas.

Bajo este enfoque se ha creado el producto turístico Rutas del Vino de España basado en la integración de actividades vitícolas, gastronómicas, 
culturales y de ocio, acompañado por una amplia oferta de alojamiento, servicios relacionados con dicha actividad y otros complementarios, dentro de una misma zona vitivinícola. En todos los casos, el denominador común es uno: el vino. Rutas del Vino de España se asienta sobre una estrategia de desarrollo socioeconómico integral del territorio, de cooperación público-privada y de valorización de la identidad y cultura vitivinícola del destino, que integra, tanto a empresas turísticas, como a otras cuyos sectores han estado tradicionalmente lejos del turismo como bodegas, enotecas, o tiendas especializadas. El producto incorpora, además, a las Administraciones Locales del territorio por donde transcurre la Ruta como gestoras de gran parte de los valores y recursos que se localizan en él. Todas las Rutas disponen de una entidad que gestiona y da cohesión a sus actuaciones; suelen ser Asociaciones o Consorcios, que planifican, gestionan, controlan y comercializan el producto turístico.

De forma general, cada Ruta debe contar con un mínimo de componentes en función de la dimensión del sector en la zona, teniendo en cuenta el número total de bodegas inscritas en el Consejo Regulador de cada Denominación de Origen y el número de municipios participantes en la Ruta (Tabla 2).

Tabla 2

Componentes mínimos de una Ruta del Vino de España

\begin{tabular}{|c|c|c|c|}
\hline \multirow{2}{*}{$\begin{array}{l}\text { Requerimientos } \\
\text { mínimos de cada } \\
\text { Ruta }\end{array}$} & \multicolumn{3}{|c|}{$\begin{array}{l}\text { Número total de bodegas inscritas en } \\
\text { el Consejo Regulador de cada DO }\end{array}$} \\
\hline & De 0 a 25 & De 26 a 50 & Más de 50 \\
\hline $\begin{array}{l}\text { Número mínimo } \\
\text { de bodegas }\end{array}$ & 5 bodegas & 7 bodegas & 10 bodegas \\
\hline \multirow{2}{*}{$\begin{array}{l}\text { Requerimientos } \\
\text { mínimos de cada } \\
\text { Ruta }\end{array}$} & \multicolumn{3}{|c|}{ Número de municipios participantes en la Ruta } \\
\hline & 1 municipio & $\begin{array}{l}\text { Más de } 1 \text { y menos } \\
\text { de } 5 \text { municipios }\end{array}$ & 5 o más municipios \\
\hline $\begin{array}{l}\text { Número mínimo } \\
\text { de establecimientos }\end{array}$ & $\begin{array}{l}3 \text { de restauración } \\
2 \text { de alojamiento } \\
1 \text { comercio } \\
\text { enológico }\end{array}$ & $\begin{array}{l}4 \text { de restauración } \\
3 \text { de alojamiento } \\
1 \text { comercio } \\
\text { enológico }\end{array}$ & $\begin{array}{l}5 \text { de restauración } \\
4 \text { de alojamiento } \\
2 \text { comercios enológicos }\end{array}$ \\
\hline $\begin{array}{l}\text { Administraciones } \\
\text { Públicas y } \\
\text { asociaciones } \\
\text { empresariales }\end{array}$ & \multicolumn{3}{|c|}{$\begin{array}{c}\text { La Administración con competencias en turismo y las asociaciones } \\
\text { empresariales de hostelería y restauración deben tener representación } \\
\text { en el Ente Gestor }\end{array}$} \\
\hline
\end{tabular}

Fuente: Elaboración propia a partir del Informe Club del Producto Rutas del Vino de España, disponible en www.acevin.es.

A pesar de estos requerimientos, la Comisión de Expertos supervisora de las Rutas del Vino de España podrá conceder la marca a una ruta turística que no cumpla con las exigencias mínimas anteriores si se estima que dicha Ruta es representativa del territorio y su $D O P$ presenta un alto valor vitivinícola. 
El producto Rutas del Vino de España nace en 2001, cuando ACEVIN consigue el apoyo de la Secretaría General de Turismo para empezar a trabajar en la definición y elaboración de las normas que regularan este producto turístico. La colaboración se inició en el marco del Programa de Calidad en los Productos Turísticos, dentro del Plan Integral de Calidad del Turismo Español (PICTE 2000-2006) cuyo objetivo general era trabajar en el diseño y desarrollo de nuevos productos turísticos que favorecieran la diversificación y desestacionalización de la oferta turística española. De manera que los objetivos que se persiguen a la hora de implantar una Ruta del Vino en un territorio determinado son:

- Incrementar la actividad turística en la zona donde se establece el producto turístico.

- Generar riqueza a través de actividades complementarias a la tradicional de la zona.

- Mejorar las infraestructuras del área geográfica.

- Diversificar y desestacionalizar la actividad turística en la zona.

Las Rutas que participaron inicialmente en el proyecto fueron: Jumilla, La Mancha, Montilla-Moriles, Penedés, Rías Baixas y Utiel-Requena. Desde entonces su desarrollo ha atravesado por cinco fases cuyos principales hitos se presentan en la Tabla 3.

\section{Tabla 3}

Fases y principales hitos del producto Rutas del Vino de España

\begin{tabular}{|c|l|}
\hline Fases & \multicolumn{1}{c|}{ Principales hitos de cada fase } \\
\hline $\begin{array}{c}\text { Primera Fase } \\
2001-2002\end{array}$ & - $\begin{array}{l}\text { Seis Rutas participaron inicialmente en el proyecto: Jumilla, La Mancha, } \\
\text { Montilla-Moriles, Penedés, Rías Baixas y Utiel-Requena. }\end{array}$ \\
\hline Segunda Fase & - $\begin{array}{l}\text { Se incorporaron cinco nuevos Rutas: Marco de Jerez, Ribera del Duero, } \\
\text { La Rioja Alavesa, Somontano e Ycoden-Daute-Isora }{ }^{34} \text {. }\end{array}$ \\
$\begin{array}{l}\text { Se creó el Comité de Gestión de las Rutas del Vino de España como } \\
\text { órgano, dentro de la estructura de ACEVIN, encargado del control de la } \\
\text { gestión y de las actividades de certificación y promoción de las Rutas del } \\
\text { Vino. }\end{array}$ \\
\hline
\end{tabular}

\footnotetext{
${ }^{34}$ Esta Ruta no se consolidó y perdió la condición de Ruta del Vino de España.
} 
Tabla 3 (continuación)

Fases y principales hitos del producto Rutas del Vino de España

\begin{tabular}{|c|c|}
\hline Fases & Principales hitos de cada fase \\
\hline $\begin{array}{c}\text { Tercera Fase } \\
2005-2006\end{array}$ & $\begin{array}{l}\text { - Se adhirieron seis nuevas Rutas: Navarra, Condado de Huelva, Bullas, } \\
\text { Ribeiro, Tacoronte-Acentejo }{ }^{35} \text { y La Rioja. } \\
\text { - } \quad \text { Se hizo una completa revisión de todo el Sistema Rutas del Vino de } \\
\text { España actualizando el Manual de Producto Rutas del Vino de España } \\
\text { para ajustarlo a la realidad y demanda del mercado. } \\
\text { - } \quad \text { Se aprobó el Sistema de Certificación de las Rutas del Vino de España. } \\
\text { - Se estableció un Plan de Marketing y Promoción de las Rutas del Vino } \\
\text { de España a nivel nacional e internacional para el período 2006-2010. } \\
\text { - Al finalizar este periodo, se había constituido el Club del Producto Rutas } \\
\text { del Vino de España con un total de } 17 \text { Rutas, } 11 \text { de ellas certificadas. }\end{array}$ \\
\hline $\begin{array}{c}\text { Cuarta Fase } \\
2007-2008\end{array}$ & $\begin{array}{l}\text { - } \quad \text { Se unieron dos nuevas Rutas: Alicante y Ribera del Guadiana. } \\
\text { - } \quad \text { Se aumentó el número de Rutas certificadas a } 13 . \\
\text { - } \quad \text { que constitú a actualizar el Manual de Producto Rutas del Vino de España } \\
\text { - Se crea el Observatorio de las Rutas del Vino de España en } \\
\text { colaboración con las } 19 \text { Rutas que entonces conformaban el Club. }\end{array}$ \\
\hline $\begin{array}{l}\text { Quinta Fase } \\
2009-2010\end{array}$ & $\begin{array}{l}\text { - Se incorporaron tres nuevas Rutas: Lleida-Costers del Segre, El Bierzo y } \\
\text { Campo de Borja y se procedió a la certificación de otras } 3 \text { Rutas del } \\
\text { Vino. }\end{array}$ \\
\hline
\end{tabular}

Fuente: Elaboración propia a partir de la información publicada por ACEVIN.

Desde 2001 hasta hoy el trabajo desarrollado ha permitido consolidar una marca turística de calidad que se ha convertido en un referente nacional e internacional en enoturismo. A ello ha contribuido: el apoyo recibido por los Ministerios de Industria, Turismo y Comercio, y de Medio Ambiente y Medio Rural y Marino; el interés creciente que ha despertado entre los medios de comunicación y los agentes del sector turístico; y, la evolución del número de enoturistas que las han visitado y que no ha parado de crecer incluso durante estos tres últimos años de crisis en el sector turístico nacional. El producto Rutas del Vino de España cuenta actualmente con 21 rutas, de las cuales 16 están certificadas ${ }^{36}$, hallándose las 5 restantes en proceso de certificación ${ }^{37}$ (Mapa 1).

${ }^{35}$ Desde 2006 pasa a denominarse Ruta del Vino de Tenerife, obteniendo la certificación de Ruta del Vino de España un año después. Aunque inicialmente recibió el nombre de TacoronteAcentejo, debido a que sólo estaba integrada esta Denominación de Origen, con la incorporación del municipio de La Orotava, se ha procedido a modificar su denominación. Incluye la DO Tacoronte-Acentejo y la DO Valle de Orotava y es la única Ruta certificada existente en Canarias. Puede encontrarse más información en: www.rutasyvinos.com.

36 Éstas son: Caminos del Vino de La Mancha, Ruta del Vino de Jumilla, Ruta del Vino Somontano, Ruta del Vino y del Brandy del Marco de Jerez, Ruta del Vino Bullas, Ruta del Vino de Montilla-Moriles, Ruta del Vino Ribera del Duero, Ruta del Vino de Ribeiro, Ruta del Vino de las Rías Baixas, Ruta del Vino Rioja-Alavesa, Ruta del Vino de Navarra, Ruta del 


\section{Mapa 1}

Localización del Producto Rutas del Vino de España. Situación a abril de 2011

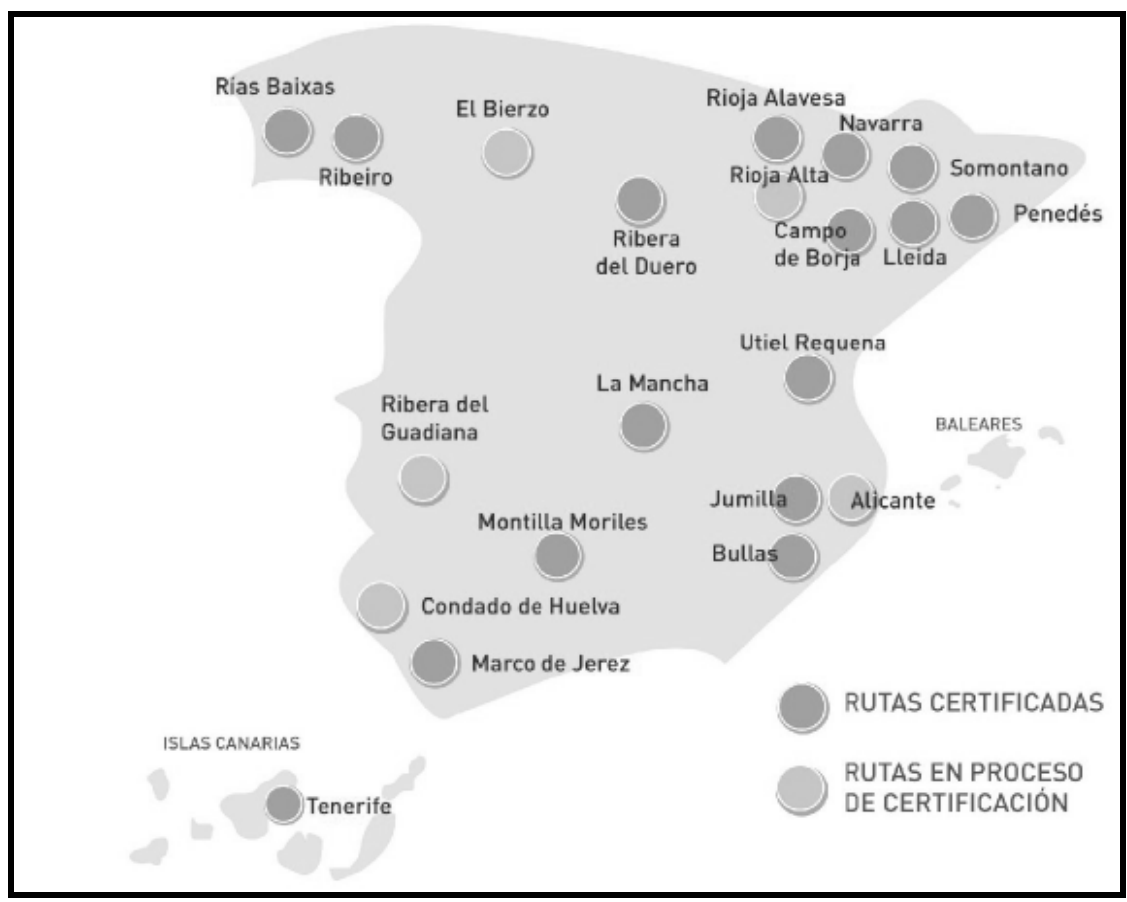

Fuente: Información publicada por ACEVIN, disponible en: www.rutasdelvinodeespaña.com.

Una Ruta del Vino certificada es aquella que acredita periódicamente el cumplimiento de los criterios de calidad que ACEVIN y la Secretaría General de Turismo y Comercio Interior del Ministerio de Industria, Turismo y Comercio han establecido en el Manual de Producto Turístico Rutas del Vino de $E_{\text {spaña }}{ }^{38}$, en el que también se recoge la metodología para su implantación y posterior certificación por parte del Comité de Gestión y Certificación de las Rutas del Vino de España del que forman parte tanto ACEVIN como la Secretaría General. El proceso consta de tres fases:

Vino Lleida, Ruta del Vino de Tenerife, Ruta del Vino y del Cava del Penedés, Ruta del Vino de La Garnacha (Campo de Borja) y Ruta del Vino Utiel-Requena.

${ }^{37}$ En esta situación se encuentran: Ruta del Vino de Alicante, Ruta del Vino del Bierzo, Ruta del Vino Condado de Huelva, Ruta del Vino Ribera del Guadiana y Ruta del Vino Rioja Alta.

${ }^{38}$ Además de los parámetros de calidad que debe cumplir una Ruta del Vino de España, el Manual establece también los requisitos del sistema de gestión, señalización, promoción y comercialización, así como los que deben cumplir todos los establecimientos que forman parte de la Ruta. Es un documento que se actualiza periódicamente para ajustarse a la demanda del mercado. 
- Fase de lanzamiento. Durante esta fase las entidades públicas y privadas implicadas en el producto turístico deben prepararse para cumplir las exigencias que requiere la Ruta al objeto de conseguir la certificación: crear un Ente Gestor de la Ruta, designar a un gerente y adecuar las instalaciones y servicios de los establecimientos adheridos a los requisitos de calidad establecidos.

- Fase de desarrollo. Tiene una duración de dos años y se inicia una vez conseguida la certificación como Ruta del Vino de España. En este periodo, la Ruta se compromete a poner en marcha las actuaciones recogidas en el Manual. Si el proceso de certificación finaliza con una valoración satisfactoria, el destino mantendrá su certificación y pasará a la siguiente fase: la de consolidación. Si, por el contrario, la valoración es negativa, el destino pierde su certificación y es penalizado impidiendo que pueda volver a solicitar la certificación durante el plazo de un año. De este modo se garantiza que cada Ruta del Vino continúe en su esfuerzo por mantener y mejorar los indicadores de calidad, incluso después de haber obtenido la certificación.

- Fase de consolidación. Cada dos años se comprueba si la Ruta mantiene el grado de exigencia, tanto en lo referente a los establecimientos adheridos como a las actuaciones de la propia Ruta. Si se obtiene una valoración negativa, el destino pierde la distinción de Ruta del Vino de España, debiendo volver a solicitar su certificación cuando considere que cumple los requisitos mínimos.

En los últimos tres años han sido numerosas las muestras de reconocimiento que ha recibido este producto turístico. En la Feria de Turismo FITUR, en su edición de 2008, las Rutas del Vino de España fue galardonado como mejor producto de turismo activo. En 2009, el Consejo de Ministros aprobó el Plan de Promoción Internacional del Turismo Enogastronómico, con una dotación de 9 millones de euros, en el que las Rutas del Vino de España desempeñan un importante papel. En julio de 2010, la Secretaría General de Turismo y Comercio Interior, firmó con ACEVIN y con la Sociedad Estatal para la Gestión de la Innovación y las Tecnologías Turísticas (SEGITTUR), el Plan Anual de Actuación para el Desarrollo y Promoción Turística del Producto Rutas del Vino de España, por el que el Instituto de Turismo de España (Turespaña) se compromete a continuar trabajando en el canal temático sobre estas Rutas, dentro de su portal de promoción turística www.spain.info, incorporando aquellas que se vayan certificando. Finalmente, Rutas del Vino de España, en colaboración con el MARM, ha puesto en marcha el proyecto piloto titulado Hacia un modelo de competitividad, sostenibilidad y gobernanza en el Medio Rural: Territorio Enoturístico Socialmente Responsable (TESR) que 
pretende aumentar los estándares de calidad de este producto ampliándolos a todas las áreas posibles ${ }^{39}$.

Ahora bien, de nada habría servido todo este esfuerzo institucional si no hubiera habido una respuesta favorable desde la demanda. Aunque es pronto para valorar el éxito de este producto y evaluar sus impactos sobre el territorio, sí se pueden ofrecer algunos datos que pueden mostrar indicios de ello.

Según la Encuesta de Movimientos Turísticos en Frontera (FRONTUR) del Ministerio de Industria, Turismo y Comercio, en 2010 España recibió un total de 93,7 millones de visitantes extranjeros, de los cuales 52,7 millones eran turistas y 41,0 excursionistas. Ese mismo año, el número de personas que hicieron uso de los servicios de turismo rural en España ascendió a 2.666.449, con una estancia media de 2,88 pernoctaciones, descendiendo un $1,9 \%$ y un $1,5 \%$, respectivamente, en relación con los valores registrados en 2009. Sin embargo, el número de visitantes que recibieron las bodegas asociadas a las Rutas del Vino de España, en 2010, ascendió a 1.441.316, lo que representa un incremento del $1,3 \%$ en relación con las cifras que se obtuvieron en 2009 , y del $20 \%$ respecto a las de 2008. La Ruta del Vino más visitada fue la del Vino y el Cava del Penedés, con 459.400 turistas, seguida por la Ruta del Vino y del Brandy del Marco de Jerez, con 455.854 visitas, acogiendo ambas Rutas el $63,5 \%$ de los enoturistas. Les siguen en importancia la Ruta del Vino Rioja Alavesa y la Ruta del Vino Ribera del Duero. Estos datos indican que, si bien el turismo rural se ha resentido por la crisis económica que tan duramente está castigando a España, el turismo enológico no sólo no ha disminuido sino que ha aumentado, convirtiéndose en un complemento interesante al turismo rural tradicional.

Otro dato significativo que debe tenerse en cuenta es el mes en el que los turistas deciden recorrer alguna de las Rutas (Gráfico 3), circunstancia ésta que hace del enoturismo una actividad económica desestacionalizada, en relación con lo que sucede en el turismo, en general. Como puede observarse, más del $84 \%$ de los enoturistas que decidieron visitar alguna de las Rutas del Vino de España en los tres últimos años (el 84,2\%, en 2010), lo hicieron fuera de los meses de julio y agosto, lo que permite que muchas instalaciones turísticas, principalmente del medio rural, puedan mantener su actividad a lo largo de todo el año.

${ }^{39}$ Las veintiuna Rutas participan en el programa que se extenderá hasta finales de 2011. Durante la primera fase de este proyecto, que finalizó en diciembre de 2010, se desarrollaron más de 100 actuaciones. 


\section{Gráfico 3}

Evolución del número de enoturistas que visitan las Rutas del Vino de España

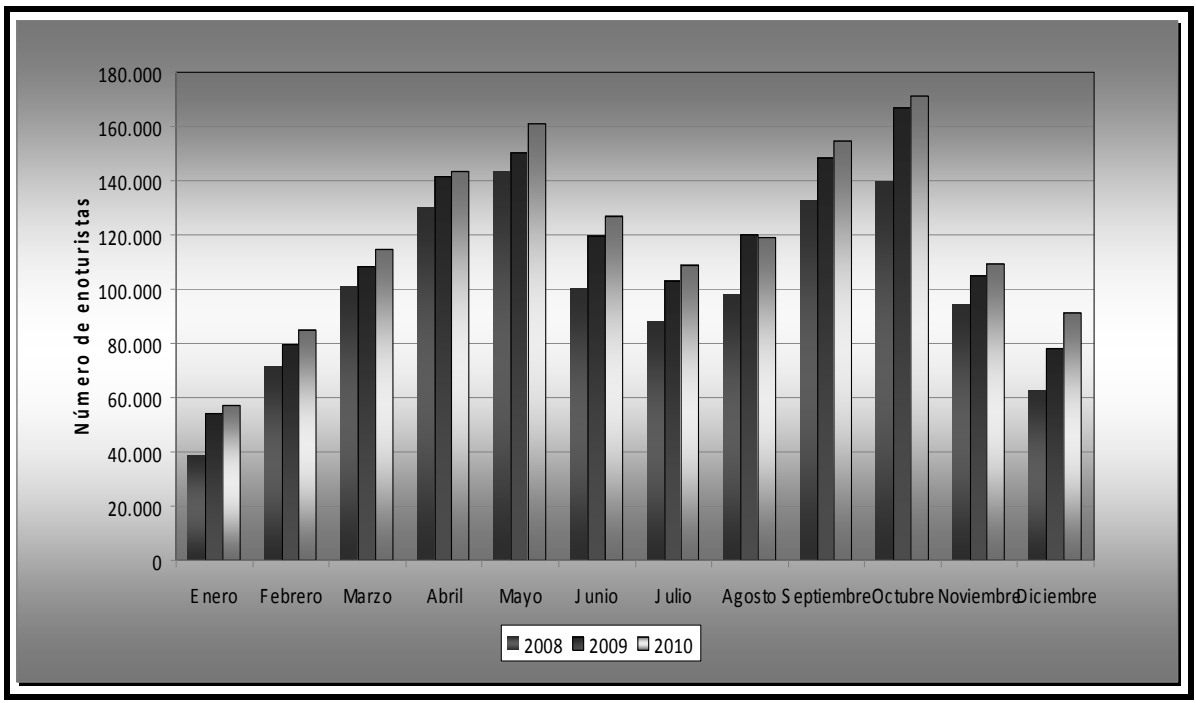

Fuente: Elaboración propia a partir de la información publicada por ACEVIN, disponible en: www.rutasdelvinodeespaña.com.

Las veintiuna Rutas del Vino de España presentan un gran número de características comunes, como común es también el producto básico que ofrecen, pero difieren entre ellas, sobre todo, en el entorno físico en el que se ubican. No es objeto de este trabajo realizar un análisis exhaustivo de las semejanzas y diferencias de todas ellas, por ello se han escogido como ejemplo dos Rutas diferentes (Ribera del Duero y Navarra), cuyas principales características se presentan en la Tabla 4, en las que se muestra el elevado grado de implicación de los agentes económicos que operan en el territorio (bodegas, Grupos de Acción Local, asociaciones sin animo de lucro, empresas de servicios, Administraciones Públicas,...) que dan fe de los efectos de arrastre que se generan a partir del vino y del aprovechamiento de los recursos endógenos del territorio en el que se ubica cada Ruta. 
Tabla 4

Principales características de las Rutas del Vino de Ribera del Duero y Navarra

\begin{tabular}{|c|c|c|}
\hline Concepto & Ruta del Vino Ribera del Duero & Ruta del Vino de Navarra \\
\hline $\begin{array}{c}\text { Denominación de } \\
\text { Origen }\end{array}$ & Ribera del Duero & Navarra \\
\hline $\begin{array}{c}\text { Superficie acogida a la } \\
\text { DO en la campaña } \\
2007 / 08 \text { (hectáreas) }\end{array}$ & 20.638 & 17.526 \\
\hline $\begin{array}{l}\text { Número de viticultores } \\
\text { acogidos }\end{array}$ & 8.303 & 4.930 \\
\hline $\begin{array}{l}\text { Tipo de vinos } \\
\text { amparados }\end{array}$ & $\begin{array}{l}\text { Tintos } \\
\text { Rosados }\end{array}$ & $\begin{array}{c}\text { Tintos } \\
\text { Rosados } \\
\text { Blancos } \\
\text { Vino de licor moscatel }\end{array}$ \\
\hline $\begin{array}{l}\text { Fecha certificación de } \\
\text { la Ruta }\end{array}$ & Diciembre de 2010 & Junio de 2006 \\
\hline $\begin{array}{l}\text { Distribución de socios } \\
\text { por tipo de entidad }\end{array}$ & $\begin{array}{l}53 \text { Ayuntamientos }\left(^{*}\right) \\
1 \text { Consejo Regulador } \\
9 \text { Asociaciones relacionadas con el } \\
\text { turismo y la vitivinicultura } \\
33 \text { Bodegas } \\
16 \text { Alojamientos hoteleros } \\
18 \text { Restaurantes } \\
8 \text { Enotecas y comercios } \\
\text { especializados } \\
6 \text { Museos o Centros de } \\
\text { Interpretación del Vino } \\
20 \text { Establecimientos de ocio } \\
\text { complementario }\end{array}$ & $\begin{array}{l}37 \text { Ayuntamientos } \\
15 \text { Bodegas, } \\
16 \text { Alojamientos } \\
1 \text { Museo de la Viña y el Vino } \\
\text { de Navarra } \\
15 \text { Restaurantes y bares } \\
2 \text { Enotecas y comercios } \\
\text { especializados } \\
1 \text { Hípica } \\
1 \text { Empresa de servicios } \\
\text { turísticos }\end{array}$ \\
\hline \multirow{2}{*}{$\begin{array}{l}\text { Número de visitantes } \\
\text { en } 2009 \text { y } 2010\end{array}$} & 2010 & 2010 \\
\hline & 131.194 & 12.097 \\
\hline
\end{tabular}

${ }^{*}$ ) Pertenecientes a cuatro provincias de la región, están distribuidos del siguiente modo: 35 corresponden a la provincia de Burgos, 1 a la de Segovia, 5 a la de Soria y 12 a la de Valladolid.

Fuente: Elaboración propia a partir de la información proporcionada por las diferentes Rutas.

Como se ha puesto de manifiesto a lo largo de este trabajo, el vino puede ser la excusa utilizada como reclamo, pero existen también otros elementos de atracción turística como el patrimonio arquitectónico, histórico, cultural y natural, que se complementan con el vino y su cultura, constituyendo éste el eje vertebrador de la estrategia de desarrollo. Como ejemplos se reflejan en las Tablas 5 y 6 las propuestas que ofrecen la Ruta del Vino Ribera del Duero y la Ruta del Vino de Navarra, conformando un conjunto de lugares y actividades de interés. 


\section{Tabla 5}

Propuestas de turismo y ocio de la Ruta del Vino Ribera del Duero

\begin{tabular}{|c|c|}
\hline $\begin{array}{c}\text { Denominación de la } \\
\text { propuesta }\end{array}$ & Descripción de las actividades \\
\hline $\begin{array}{l}\text { Aprender a catar un } \\
\text { vino }\end{array}$ & $\begin{array}{l}\text { Conjunto de establecimientos que a lo largo de la Ruta del Vino Ribera } \\
\text { de Duero ofrecen al visitante la posibilidad de disfrutar de una cata } \\
\text { orientada por expertos enólogos. }\end{array}$ \\
\hline Paisajes inolvidables & $\begin{array}{l}\text { Colección de lugares desde donde se obtienen las mejores vistas de la } \\
\text { Ribera, con viñedos y bodegas. }\end{array}$ \\
\hline Ruta de los Castillos & $\begin{array}{l}\text { Uno de los elementos arquitectónicos más repetidos y singulares del } \\
\text { territorio que comprende la Ribera del Duero es el castillo. Los mejores } \\
\text { ejemplos son la Atalaya Árabe de San Esteban de Gormaz, el Castillo } \\
\text { de Peñaranda de Duero, el Torreón del Siglo XII en Hoyales de Roa, el } \\
\text { Palacio de Zúñiga en Curiel de Duero, las Ruinas del Castillo de } \\
\text { Torregalindo, las Ruinas del Castillo y murallas de Haza, la Torre } \\
\text { Castillo de Langa de Duero y el Torreón de los Guzmanes en } \\
\text { Caleruega. }\end{array}$ \\
\hline $\begin{array}{l}\text { Los primeros } \\
\text { pobladores }\end{array}$ & $\begin{array}{l}\text { Se han excavado, acondicionado y abierto al público distintos } \\
\text { yacimientos arqueológicos y se han equipado varios centros didácticos } \\
\text { que acercan las antiguas civilizaciones a los visitantes. Los mejores } \\
\text { ejemplos son: la Villa Romana de Santa Cruz en Baños de } \\
\text { Valdearados, el Poblado Pintia Vacceo en Padilla de Duero o el } \\
\text { Yacimiento-Aula de Rauda en Roa. }\end{array}$ \\
\hline $\begin{array}{l}\text { Un fin de semana en } \\
\text { las bodegas }\end{array}$ & $\begin{array}{l}\text { Visita a las bodegas subterráneas del casco histórico de Aranda de } \\
\text { Duero; siete kilómetros de túneles y galerías excavadas entre los siglos } \\
\text { XIII y XVIII para elaborar vino, gracias a sus niveles constantes de } \\
\text { humedad y temperatura }\left(11-13^{\circ} \mathrm{C}\right) \text {. }\end{array}$ \\
\hline De tapas por Aranda & $\begin{array}{l}\text { En Aranda de Duero, la mayor de las poblaciones de la Ribera del } \\
\text { Duero, existe un gran número de mesones y restaurantes que, además } \\
\text { de una buena mesa, ofrecen a los amantes del enoturismo tapas y } \\
\text { raciones, para disfrutar de esta costumbre gastronómica española. }\end{array}$ \\
\hline $\begin{array}{l}\text { El refugio de rapaces } \\
\text { de Montejo de la Vega } \\
\text { de la Serrezuela }\end{array}$ & $\begin{array}{l}\text { Situado en las Hoces del Riaza, es la primera reserva natural privada } \\
\text { de España, por iniciativa de Félix Rodríguez de la Fuente. A partir de } \\
\text { aquí, la Confederación Hidrográfica del Duero fundó el Refugio de } \\
\text { Rapaces del Embalse de Linares del Arroyo desde donde avistar un } \\
\text { buen número de rapaces ibéricas y especialmente el buitre leonado. }\end{array}$ \\
\hline Vinoterapia y Spa & $\begin{array}{l}\text { La vinoterapia se está consolidando como un tratamiento de salud y } \\
\text { belleza muy apreciado entre los visitantes a las distintas Rutas del Vino } \\
\text { de España. La de Ribera del Duero alberga instalaciones para su } \\
\text { disfrute. }\end{array}$ \\
\hline $\begin{array}{l}\text { El Parque del } \\
\text { Románico }\end{array}$ & $\begin{array}{l}\text { Ubicado en San Esteban de Gormaz, dispone de una serie de } \\
\text { maquetas que muestran los monumentos románicos más } \\
\text { emblemáticos de Castilla y León como: la Basílica de San Vicente de } \\
\text { Ávila, la Colegiata de Santa María la Mayor de Toro, San Juan de } \\
\text { Rabanera de Soria, la iglesia de Santa María La Antigua de Valladolid, } \\
\text { la de San Marcos de Salamanca y la de San Martín de Frómista, entre } \\
\text { otros. }\end{array}$ \\
\hline $\begin{array}{l}\text { Lugares para comprar } \\
\text { vino }\end{array}$ & Bodegas y comercios donde adquirir vino a lo largo de toda la Ruta. \\
\hline
\end{tabular}

Fuente: Elaboración propia a partir de la información proporcionada por el Consorcio y la publicada en: www.rutadelvinoriberadelduero.es y www.riberate.com. 
Tabla 6

Propuestas de turismo y ocio de la Ruta del Vino de Navarra

\begin{tabular}{|l|l|}
\hline $\begin{array}{l}\text { Denominación de la } \\
\text { propuesta }\end{array}$ & \multicolumn{1}{c|}{ Descripción de las actividades } \\
\hline $\begin{array}{l}\text { Vino y patrimonio } \\
\text { medieval }\end{array}$ & $\begin{array}{l}\text { Cascos históricos, fortalezas y palacios como: el Cerco de Artajona; el } \\
\text { Palacio Real de Olite, símbolo del esplendor de la Corte Real; la Torre } \\
\text { Medieval de Olcoz; Ujué; y, el Monasterio de la Oliva. }\end{array}$ \\
\hline Vino y románico & $\begin{array}{l}\text { Muestras del románico rural como la ermita de Eunate, la iglesia de } \\
\text { Catalain o las criptas de Orisoain y San Martín de Unx. }\end{array}$ \\
\hline $\begin{array}{l}\text { Vino y Camino de } \\
\text { Santiago }\end{array}$ & $\begin{array}{l}\text { La ruta del Vino de Navarra es un cruce de caminos de peregrinaje a } \\
\text { Santiago, con un gran número de monumentos surgidos a su amparo. }\end{array}$ \\
\hline $\begin{array}{l}\text { Vino y vestigios del } \\
\text { pasado }\end{array}$ & $\begin{array}{l}\text { Yacimientos como el Desploblado Medieval de Rada, el Poblado de la } \\
\text { Edad del Hierro de las Eretas o la Ciudad Romana de Andelos, } \\
\text { excepcional por la conservación de su sistema de abastecimiento de } \\
\text { aguas, donde se puede visitar la presa, el depósito regulador, el } \\
\text { acueducto o el Castellum Aquae. }\end{array}$ \\
\hline Vino y biodiversidad & $\begin{array}{l}\text { La transición orográfica entre la llanura y la montaña permite el contraste } \\
\text { y la confluencia de la flora y la fauna de la comarca. Como ejemplos } \\
\text { más importantes están las Bardenas Reales, las Nekeas o la Laguna de } \\
\text { Pitillas. }\end{array}$ \\
\hline Vino y fiesta & $\begin{array}{l}\text { Conjunto de propuestas festivas que recuperan elementos } \\
\text { patrimoniales, gastronómicos, culturales, vitivinícolas, folklóricos o } \\
\text { históricos. }\end{array}$ \\
\hline $\begin{array}{l}\text { Vino, senderos y } \\
\text { miradores }\end{array}$ & $\begin{array}{l}\text { La geografía de la Ruta favorece el senderismo y los paseos en bicicleta } \\
\text { que permiten disfrutar de la Red de Miradores y Senderos Interpretativos } \\
\text { de la Ruta del Vino de Navarra. }\end{array}$ \\
\hline Vino y micología & $\begin{array}{l}\text { El Valle de la Valdorba destaca por el cultivo de la trufa. Se organizan } \\
\text { visitas a truferas que tienen su momento más importante con la Fiesta } \\
\text { de la Trufa en Orisoain. }\end{array}$ \\
\hline $\begin{array}{l}\text { Vino y observación } \\
\text { de aves }\end{array}$ & $\begin{array}{l}\text { La riqueza de la avifauna de la zona y las buenas condiciones de } \\
\text { observación de las aves hacen de este Ruta un lugar ideal para los } \\
\text { amantes de la ornitología. }\end{array}$ \\
\hline
\end{tabular}

Fuente: Elaboración propia a partir de la información proporcionada por el Consorcio de Desarrollo de la Zona Media, órgano gestor de la Ruta. Más información en: www.rutadelvinodenavarra.com.

\section{CONCLUSIONES}

La importancia del viñedo en la economía agraria a lo largo de la historia es incuestionable. El vino, que durante miles de años ha acompañado la evolución de pueblos y civilizaciones y que desde los orígenes de la Economía ha servido como acicate para el desarrollo de numerosos conceptos que conforman el corpus de esta Ciencia Social, se enfrenta hoy a una serie de retos difíciles de abordar. Sometido a un sinfín de regulaciones, a partir de 2015 o 2018, según los casos, se liberalizará, lo que representa un peligro para todas aquellas denominaciones de calidad que, a lo largo de décadas, han estado sometidas a rigurosos sistemas de control que les ha permitido mejorar su calidad y posicionarse en un mercado cada vez más competitivo y globalizado. Un sector con importantes efectos de arrastre sobre otras actividades económicas del 
territorio que utilizan el vino como input o como output, en el que la innovación se hace necesaria para hacer frente a las exigencias de un mercado cada vez más complejo. En este contexto se inserta el enoturismo; es decir, el desarrollo de actividades turísticas, de ocio y tiempo libre dedicadas al descubrimiento y disfrute cultural y enológico de la viña, el vino y su territorio.

La principal fórmula para organizar el enoturismo es la de crear itinerarios o rutas del vino, que ofrecen al turista la oportunidad de conocer los recursos naturales, históricos y culturales que caracterizan los territorios visitados, y que se identifican con entidades socio-territoriales que pueden considerarse una variante del concepto marshalliano de distrito industrial. Todo ello aprovechando que el vino es un "producto intensivo en territorio" (PIT), al contener un elevado componente territorial referido al lugar en el que se produce.

Partiendo de este marco teórico y asumiendo que el vino puede utilizarse como recurso para generar un flujo de visitantes que desean descubrir no sólo el origen del producto en sí mismo, sino también conocer los lugares y los modos de producción, se han creado: la Asociación Española de Pequeñas y Medianas Ciudades Vitivinícolas (ACEVIN); y, el producto Rutas del Vino de España, que cuenta actualmente con veintiuna Rutas, de las cuales dieciséis se hallan certificadas.

Han sido numerosas las muestras de reconocimiento que ha recibido este producto turístico en los últimos tres años, pero de nada habría servido este esfuerzo institucional si no hubiera habido una respuesta favorable desde la demanda. Aunque es pronto para valorar el éxito de este producto y evaluar sus impactos sobre el territorio, sí se pueden ofrecer algunos datos que pueden mostrar indicios de ello. Frente a la caída experimentada, en 2010, por el número de personas que hicieron uso de los servicios de turismo rural en España, el número de visitantes que recibieron las bodegas asociadas a las Rutas del Vino de España, se incrementó. Estos datos indican que, si bien el turismo rural se ha resentido por la crisis económica que tan duramente está castigando a España, el turismo enológico no sólo no ha disminuido sino que ha aumentado, convirtiéndose en un complemento interesante al turismo rural tradicional, máxime si se tienen en cuenta los meses en los que los turistas deciden recorrer alguna de las Rutas (mayo, septiembre y octubre), circunstancia ésta que hace del enoturismo una actividad económica desestacionalizada.

Como se ha puesto de manifiesto a lo largo de este trabajo, el vino puede ser la excusa utilizada como reclamo, pero existen también otros elementos de atracción turística como el patrimonio arquitectónico, histórico, cultural y natural, que se complementan con el vino y su cultura, constituyendo éste último el eje vertebrador de la estrategia de desarrollo. 


\section{REFERENCIAS BIBLIOGRÁFICAS}

ASERO, V. y PATTI, S. (2009): "From wine production to wine tourism experience: The case of Italy". American Association of Wine Economists Working Paper, No 42.

ASOCIACIÓN ESPAÑOLA DE CIUDADES DEL VINO (ACEVIN) (2006): El proceso de certificación de una Ruta del Vino. Disponible en: http://www.ciudadesdelvino.com/ RutasVino/popTexto.asp?idTexto=procesoCertificacion. [Último acceso: Febrero de 2011].

ASOCIACIÓN ESPAÑOLA DE CIUDADES DEL VINO (ACEVIN) (2009): Informe de visitantes a bodegas asociadas a las Rutas del Vino de España. Año 2008. Disponible en:http://www.wineroutesofspain.com/static/publicaciones/otros/Análisis\%20Visitantes\%20Bodegas\%20Rutas\%20del\%20Vino \%202008.pdf. [Último acceso: Febrero de 2011].

ASOCIACIÓN ESPAÑOLA DE CIUDADES DEL VINO (ACEVIN) (2010): Informe de visitantes a bodegas asociadas a las Rutas del Vino de España. Año 2009. Disponible en:http://www.wineroutesofspain.com/static/publicaciones/otros/An\%C3\%A1lisis\%20Visitantes\%20Bodegas\%20Rutas\%20del\% 20Vino\%202009.pdf. [Último acceso: Febrero de 2011].

ASOCIACIÓN ESPAÑOLA DE CIUDADES DEL VINO (ACEVIN) (2011): Informe de visitantes a bodegas asociadas a las Rutas del Vino de España. Año 2010. Disponible en:http://www.wineroutesofspain.com/static/publicaciones/otros/Análisis\%20Visitantes\%20Bodegas\%20Rutas\%20del\%20Vino \%202010.pdf. [Último acceso: Abril de 2011].

ASOCIACIÓN ESPAÑOLA DE CIUDADES DEL VINO (ACEVIN): Rutas del Vino de España. www.rutasdelvinodeespaña.com. [Último acceso: Febrero de 2011].

ASOCIACIÓN ESPAÑOLA DE CIUDADES DEL VINO (ACEVIN): Territorios Enoturísticos Sostenibles y Socialmente Responsables. Disponible en: http://www.enoturismoresponsable.es. [Último acceso: Marzo de 2011].

BECATTINI, G. (2005): La oruga y la mariposa. Un caso ejemplar de desarrollo en la Italia de los distritos industriales: Prato (1954-1993). Valladolid. Secretariado de Publicaciones e Intercambio Editorial. Universidad de Valladolid. Traducción al español del libro: Il bruco e la farfalla. Prato: una storia esemplare dell'Italia dei distretti.

BOLETÍN OFICIAL DEL ESTADO (1992): Orden de 1 de diciembre de 1992 por la que se aprueba el Reglamento de la Denominación de Origen Ribera del Duero y de su Consejo Regulador. Disponible en: http://www.boe.es/boe/dias/1992/12/10/pdfs/A41829-41837.pdf. [Último acceso: Marzo de 2011].

BRUWER, J. (2003): "South African wine routes: Some perspectives on the wine tourism industry's structural dimensions and wine tourism product". Tourism Management, No 24: pp.423-435. 
CÁMARA DE COMERCIO E INDUSTRIA DE VALENCIA (2010). El Enoturismo 2010. Disponible en: http://www.camaravalencia.com/camaraonline/docs/2010/Turismo/Informe_Enoturismo2010.pdf. [Último acceso: Febrero de 2011].

COMISIÓN EUROPEA. DIRECCIÓN GENERAL DE AGRICULTURA Y DESARROLLO RURAL: Mercados Agrícolas: Vino. Disponible en: http://ec.europa.eu/agriculture/markets/wine/index_es.htm. [Último acceso: Febrero de 2011].

CONSEJO DE MINISTROS (2009): Acuerdo por el que se aprueba el Plan de Promoción Internacional del Turismo Enogastronómico y se encomienda al Ministerio de Industria, Turismo y Comercio el impulso a la creación del Club del producto "Saboreando España" y la organización del I Congreso Europeo de Gastronomía y Turismo. Disponible en: http://www.lamoncloa.es/NR/rdonlyres/3A0CA95F-4B7B-49F6-8595-

5C6C1D3CBADE/97407/refc20090724.pdf [Último acceso: Enero de 2011].

CHAIKIND, S. (2010): "The role of viticulture and enology in the development of economic thought". American Association of Wine Economists Working Paper, № 74.

CHARTERS, S. y ALI-KNIGHT, J. (2002): "Who is the wine tourist". Tourism Management, $\mathrm{N}^{\circ} 23$ (3): pp:311-319.

DIRECTORATE GENERAL FOR AGRICULTURE AND RURAL DEVELOPMENT (2010). Agriculture in the EU. Statistical and Economic Information 2009. Luxemburg. European Commission.

GOBIERNO DE NAVARRA (2008): Orden Foral 376/2008, de 15 de julio, de la Consejería de Desarrollo Rural y Medio Ambiente, por la que se aprueba el Reglamento de la DO Navarra y de su Consejo Regulador. Disponible en: http://www.lexnavarra.navarra.es/detalle.asp?r=29692. [último acceso: Marzo de 2011].

HALL, C.M.; JOHNSON, G.R. y MITCHELL, R.D. (2000): "Wine tourism and regional development". En: Hall, C.M.; Sharples, E.; Cambourne, B. y Macionis, N. (Eds.): Wine tourism around the world: Development, management and markets (pp.196-225). Oxford. Butterworth Heinemann.

INSTITUTO DE TURISMO DE ESPAÑA (TURESPAÑA): Gastronomía española: Conocer la cocina española. Rutas del Vino de España. Disponible en: http://www.spain.info/es/saborea/rutas-del-vino/. [Último acceso: Febrero de 2011].

INSTITUTO ESPAÑOL DE COMERCIO EXTERIOR (ICEX): Vinos de España. Disponible en: http://www.winesfromspain.com/. [Último acceso: Febrero de 2011].

INSTITUTO NACIONAL DE ESTADÍSTICA (Varios años): Censo Agrario. Madrid. Instituto Nacional de Estadística. Se han consultado los Censos correspondientes a los años 1962, 1972, 1982, 1989 y 1999.

INSTITUTO NACIONAL DE ESTADÍSTICA (2011): Encuesta de Ocupación en 
Alojamientos de Turismo Rural. Año 2010. Disponible en: http://www.ine.es/jaxi/menu.dotype=pcaxis\&path=/t11/e162eotr\&file=inebase $\& L=0$. [Último acceso: Febrero de 2011].

JORDANA, J. (2003): "La investigación y el desarrollo tecnológico en el sector agroalimentario español". Papeles de Economía Española, № 96.

MARSHALL, A. (1890): Principles of Economics. London. McMillan.

MARTÍNEZ RUIZ, M.P. y JIMÉNEZ ZARCO, A.I. (2006): "La potenciación del origen en las estrategias de marketing de productos agroalimentarios: Objetivos, situación e implicaciones". Boletín Económico de Información Comercial Española, № 2.880: pp.13-29.

MINISTERE DE L'AGRICULTURE, DE L'ALIMENTATION, DE LA PECHE, DE LA RURALITE ET DE L'AMENAGEMENT DE LA FRANCE (2010): Les droits de plantation: un outil éprouvé et moderne de gestion harmonieuse du potentiel viticole européen. Disponible en: http://agriculture.gouv.fr/IMG/pdf/Droits_de_plantation_rapport_Vautrin_2010.pdf. [Último acceso: Febrero de 2011].

MINISTERIO DE AGRICULTURA, PESCA Y ALIMENTACIÓN (1985): Anuario de Estadística Agraria 1985. Disponible en: http://www.mapa.es/ministerio/pags/biblioteca/revistas/pdf_AEA\%5C1471-1985_15.pdf. [Último acceso: Enero de 2011].

MINISTERIO DE AGRICULTURA, PESCA Y ALIMENTACIÓN (2003): Libro Blanco de Agricultura y Desarrollo Rural. Madrid. Ministerio de Agricultura, Pesca y Alimentación.

MINISTERIO DE INDUSTRIA, TURISMO Y COMERCIO (2010): Encuesta de Movimientos Turisticos en Frontera. Disponible en: http://www.mityc.es/esES/IndicadoresyEstadisticas/DatosEstadisticos/VIII.\%20Turismo/VIII_4.pdf. [Último acceso: Febrero de 2011].

MINISTERIO DE INDUSTRIA, TURISMO Y COMERCIO (2011): Encuesta de Movimientos Turísticos en Frontera (FRONTUR). Año 2010. Nota de Prensa. http://www.mityc.es/es-es/gabineteprensa/notasprensa/documents/npfronturdic240111.pdf. [Último acceso: Febrero de 2011].

MINISTERIO DE MEDIO AMBIENTE Y MEDIO RURAL Y MARINO (2010a): Anuario de Estadística 2009. Madrid. Ministerio de Medio Ambiente y Medio Rural y Marino.

MINISTERIO DE MEDIO AMBIENTE Y MEDIO RURAL Y MARINO (2010b): Estrategia Vino 2010. Disponible en: http://www.mapa.es/alimentacion/pags/estrategia/Vino2010.pdf. [Último acceso: Febrero de 2011].

MINISTERIO DE MEDIO AMBIENTE Y MEDIO RURAL Y MARINO (2010): Consumo Alimentario en España. Disponible en: http://www.mapa.es/alimentacion/pags/consumo/año_movil_jul08_jun09/año _movil_jul08_jun09.pdf. [Último acceso: Enero de 2011].

MINISTERIO DE MEDIO AMBIENTE Y MEDIO RURAL Y MARINO: alimentación.es. Saber más para comer mejor. El vino. Disponible en: 
http://www.alimentacion.es/es/turismo_agroalimetario/rutas_del_vino/. [Último acceso: Febrero de 2011].

MIRANDA ESCOLAR, B. y PEDROSA SANZ, R. (1994): Informe sobre la primera traducción al castellano de la obra Investigación de la Naturaleza y Causas de la Riqueza de las Naciones. Versión de José Alonso Ortiz con varias notas e ilustraciones relativas a España. Mimeo.

MORENO ARRIBAS, Mª.V. (2011): El vino. Madrid. CSIC y Editorial Catarata.

PÉREZ-BUSTAMANTE, G. (1998): "La denominación geográfica: Su aplicación en la industria agroalimentaria tradicional española". Boletín Económico de Información Comercial Española, № 2.563.

RICARDO, D. (1817): Principles of Political Economy and Taxation. London. John Murray. Edición utilizada en español (1985): Principios de Economía Política y de la Tributación. Madrid. Editorial Sarpe.

SCHUMPETER, J.A. (1944): Teoría del desenvolvimiento económico. México. Fondo de Cultura Económica. Obra original publicada en 1912 bajo el título: Theory of Economic Development.

SMITH, A. (1776): An Inquiry into the Nature and Causes of the Wealth of Nations. London. Straham y Cadell. Edición utilizada en español (1794): Investigación de la Naturaleza y Causas de la Riqueza de las Naciones. 4. Volúmenes. Versión de José Alonso Ortiz. Valladolid. Oficina de la Viuda e Hijos de Santander.

SUBDIRECCIÓN GENERAL DE POLÍTICA COMERCIAL DE LA UNIÓN EUROPEA (1999): "Las indicaciones geográficas en la OMC". Boletín Económico de Información Comercial Española, № 2.613.

VARGAS, A.; PORRAS, N.; PLAZA, M. y RIQUEL, F. (2008): "Turismo enológico: Comportamiento del turista y percepción de la población residente". Papers de Turisme, № 43-44: pp.97-112.

VEBLEN, T. (1899): The Theory of the Leisure Class. Edición utilizada en español (1971): Teoría de la clase ociosa. Madrid. Fondo de Cultura Económica.

VESETH, M. (2008): "The Father of (Wine) Economics?" American Association of Wine Economists. Disponible en: http://www.wineeconomist.com/2008/04/01/the-father-of-wine-economics. [Último acceso: Enero de 2011]. 
